\title{
Lipid Peroxidation and Plant Tissue Disorders
}

\author{
held at the \\ 90th ASHS Annual Meeting \\ Nashville, Tenn. \\ 26 July 1993
}

\author{
sponsored by the \\ Environmental Stress Physiology Working Group \\ Climatology and Meteorology Working Group \\ Plant Dormancy Research Working Group \\ Pomology Working Group \\ Postharvest Working Group \\ Seed Research Working Group \\ Temperate Tree Nut Crops Working Group
}

published by the

American Society for Horticultural Science

Alexandria, VA 22314-2824

as a special insert in

HortScience 30(2), April 1995 


\title{
Workshop Papers and Authors
}

\author{
Presiding: Jeffrey A. Anderson
}

Lipid Peroxidation and Plant Tissue Disorders: Introduction to the Workshop

Jeffrey A. Anderson

Biological Roles and Biochemistry of the Lipoxygenase Pathway

Harold W. Gardner

Peroxidative Activity of Apple Peel in Relation to Development of Poststorage Disorders

Zhanyuan Du and William J. Bramlage

Release of Fluorescent Peroxidized Lipids from Membranes in Senescing Tissue by Blebbing of LipidProtein Particles

Katalin Hudak, Kening Yao, and J.E. Thompson

Toward a Comprehensive Model for Lipid Peroxidation in Plant Tissue Disorders

Robert L. Shewfelt and Albert C. Purvis

\section{Lipid Peroxidation and Plant Tissue Disorders: Introduction to the Workshop}

\author{
Jeffrey A. Anderson \\ Department of Horticulture and Landscape Architecture, Oklahoma State University, Stillwater, OK 74078
}

\begin{abstract}
Among the lipid peroxidation reactions, the addition of molecular $\mathrm{O}_{2}$ to polyunsaturated fatty acids (PUFAs) is of particular interest in biological systems. The lipoxygenase pathway is the most-studied enzymatic pathway for oxidizing PUFAs, but nonenzymatic reactions have also been characterized. When one considers the significance of lipid peroxidation, it is surprising to discover the many diverse areas that are affected. In fact, whether one considers the process beneficial or detrimental depends on the circumstances. In situations where lipid peroxidation has been implicated in tissue damage, controversy exists over whether it is involved in the primary events causing injury or merely a by-product.

Lipid peroxidation is involved with normal developmental processes, including production of flavor and odor volatiles, formation of compounds with growth-regulator-like activities, and senescence. Characteristic flavors and aromas, such as those associated with cucumber (Cucumis sativus L.) and tomato (Lycopersicon esculentum Mill.), are due in part to the presence of various enzymes in the respective lipoxygenase pathways (Gardner, 1989). Although desirable characteristics may be imparted to foods by oxidized lipids, rancidity and other off-flavors can also develop (Perkins, 1989).

Induced defenses, including the hypersensitive response associated with resistance to pathogens and herbivore defense involving proteinase inhibitors, rely in part on oxidation of PUFAs (Farmer and Ryan, 1992). These authors proposed that methyl jasmonate, formed from linolenic acid, may serve as a secondary messenger in the lipidbased signaling pathway. A direct role of aldehydes formed from PUFAs in inhibiting fungal growth also has been established (HamiltonKemp et al., 1992).
\end{abstract}

Approved for publication by the Director, Oklahoma Agricultural Experiment Station. The cost of publishing this paper was defrayed in part by the payment of page charges. Under postal regulations, this paper therefore must be hereby marked advertisement solely to indicate this fact.
Lipid peroxidation via free-radical-mediated reactions has been implicated in abiotic stresses. Evolution of ethane, a breakdown product of linolenic acid, was detected after temperature stresses (Harber and Fuchigami, 1986; Nanaiah and Anderson, 1992) and exposure to gaseous pollutants (Kimmerer and Kozlowski, 1982). Extensive peroxidation of membrane lipids may impair function and structure, possibly through the formation of gel-phase domains in the membrane (Pauls and Thompson, 1980). A similar decrease in membrane fluidity observed in senescing tissues was blocked by a lipoxygenase inhibitor (Fobel et al., 1987), but factors such as sterol content also may be important in determining membrane lipid viscosity (Duxbury et al., 1991).

Plant cells combat the formation of free radicals with antioxidants and free-radical scavengers. Leaf senescence mediated by free radicals was related to a decrease in superoxide dismutase and catalase activity (Dhindsa et al., 1981) —enzymes that detoxify superoxide and hydrogen peroxide, respectively. Purvis and Shewfelt (1993) proposed that an accumulation of stress-triggered oxidizing agents may overcome the defensive capabilities of the cell, leading to injury.

Lipid peroxidative reactions play key roles in plant responses to biotic and abiotic stresses, developmental processes, and food quality. The papers from this workshop cover many of these areas, beginning with an overview of the lipoxygenase pathway, focusing on the biochemistry and biological roles of the two branches of the lipoxygenase pathway. Presentations dealing with specific disorders are followed by a comprehensive model addressing the question of cause and effect.

\section{Literature Cited}

Dhindsa, R.S., P. Plumb-Dhindsa, and T.A. Thorpe. 1981. Leaf senescence: Correlated with increased levels of membrane permeability and lipid peroxidation, and decreased levels of superoxide dismutase and catalase. J. Expt. Bot. 32:93-101. 
Duxbury, C.L., R.L. Legge, G. Paliyath, R.F. Barber, and J.E. Thompson. 1991. Alterations in membrane protein conformation in response to senescencerelated changes. Phytochemistry 30:63-68.

Farmer, E.E. and C.A. Ryan. 1992. Octadecanoid precursors of jasmonic acid activate the synthesis of wound-inducible proteinase inhibitors. Plant Cell 4:129-134.

Fobel, M., D.V. Lynch, and J.E. Thompson. 1987. Membrane deterioration in senescing carnation flowers. Plant Physiol. 85:204-211.

Gardner, H.W. 1989. How the lipoxygenase pathway affects the organoleptic properties of fresh fruit and vegetables, p. 98-112. In: D.B. Min and T.H. Smouse (eds.). Flavor chemistry of lipid foods. Amer. Oil Chem. Soc., Champaign, Ill.

Hamilton-Kemp, T.R., C.T. McCracken, Jr., J.H. Loughrin, R.A. Andersen, and D.F. Hildebrand. 1992. Effects of some natural volatile compounds on the pathogenic fungi Alternaria alternata and Botrytis cinerea. J. Chem. Ecol. 18:1083-1091.

Harber, R.M. and L.H. Fuchigami. 1986. The relationship of ethylene and ethane production to tissue damage in frozen rhododendron leaf disks. J. Amer. Soc. Hort. Sci. 111:434-436.

Kimmerer, T.W. and T.T. Kozlowski. 1982. Ethylene, ethane, acetaldehyde, and ethanol production by plants under stress. Plant Physiol. 69:840-847.

Nanaiah, G.K. and J.A. Anderson. 1992. Electrolyte leakage and evolution of ethylene and ethane from pepper leaf disks following temperature stress and fatty acid infiltration. J. Amer. Soc. Hort. Sci. 117:846-851.

Pauls, K.P. and J.E. Thompson. 1980. In vitro simulation of senescence-related membrane damage by ozone-induced lipid peroxidation. Nature (London) 283:504-506.

Perkins, E.G. 1989. Gas chromatography and gas chromatography-mass spectrometry of odor/flavor components in lipid foods, p. 35-56. In: D.B Min and T.H. Smouse (eds.). Flavor chemistry of lipid foods. Amer. Oil Chem. Soc., Champaign, Ill.

Purvis, A.C. and R.L. Shewfelt. 1993. Does the alternative pathway ameliorate chilling injury in sensitive plant tissues? Physiol. Plant. 88:712-718.

\title{
Biological Roles and Biochemistry of the Lipoxygenase Pathway
}

\author{
Harold W. Gardner \\ National Center for Agricultural Utilization Research, Agricultural Research Service, U.S. Department of \\ Agriculture, Phytoproducts Research, 1815 North University Street, Peoria, IL 61604
}

Comparative overview of the plant and animal kingdoms. This workshop emphasized the "dark side" of uncontrolled lipid oxidation in plants, but another aspect of this oxidative process is thought to be a "normal" part of the physiological status of the plant and animal kingdoms. That is, the so-called lipoxygenase pathway is common to plants and animals (Fig. 1). Because the pathway in plants is activated by wounding and pathogen attack, the argument can be made that the pathway is normally quiescent. In animals, certain levels of prostaglandins and lipoxygenase products are known to be maintained, but only a few studies have addressed the endogenous levels of lipoxgenase metabolites in plants (e.g., see Vick and Zimmerman, 1982). More data are available concerning endogenous levels of the lipoxygenase pathway-generated jasmonic acid family of metabolites (see review in Hamberg and Gardner, 1992). Although some lipoxygenase isoenzymes can oxidize certain glyceride lipids, it is generally acknowledged that free polyunsaturated fatty acids are the preferred substrates. In plants, a little-known portion of the pathway is how the initial step is triggered, namely the lipolytic action on glycerides. Lipoxygenase oxidation of polyunsaturated fatty acids, and metabolism of the resulting fatty acid hydroperoxides, are more thoroughly characterized. However, the biosynthesis of prostaglandins via prostaglandin endoperoxide synthase has not yet been observed in plants. There are a few reports of prostaglandins isolated from plants, but few higher plants contain the arachidonic acid necessary for the action of prostaglandin endoperoxide synthase. Since prostaglandin-like fatty acids are formed simply by peroxidative reactions of hydroperoxides of either arachidonic acid or linolenic acid (O'Connor et al., 1984), it is unlikely that the "prostaglandins" found in plants resulted from true enzymic reactions of prostaglandin biosynthesis. Because higher plants largely metabolize their endogenous polyunsaturated fatty acids, linoleic and linolenic acids, and animals use mostly arachidonic acid in these reactions, they have been called the octadecanoid and eicosanoid pathways, respectively.

André and Hou first detected lipoxygenase in plants in 1932, but its significance was not understood until about 50 years later. Novel possible physiological roles for the lipoxygenase pathway in plants are now emerging rapidly. However, prostaglandin endoperoxide synthase

The cost of publishing this paper was defrayed in part by the payment of page charges. Under postal regulations, this paper therefore must be hereby marked advertisement solely to indicate this fact. and lipoxygenase activities in animals were discovered much later (Hamberg and Samuelsson, 1974; Nugteren et al., 1966), and their physiological roles were defined quickly thereafter. Although plants and animals diverged in their evolution more than 2.5 billion years ago, there remain several common enzymic reactions in the pathway in addition to lipoxygenase. Allene oxide synthase (formerly called hydroperoxide isomerase, hydroperoxide cyclase, and hydroperoxide dehydrase) is found in plants and coral (Fig. 1), and hydroperoxide lyase has been identified in plants and fish (see review in Gardner, 1991). Interestingly, both the octadecanoid and eicosanoid pathways are often triggered by stress. Many of the physiological responses are amelioration or repair of the effects of stress. For many years, aspirin has been known to block prostaglandin formation by inhibiting prostaglandin endoperoxide synthase activity. Recently, Peña-Cortés et al. (1993) reported that aspirin in plants also inhibits allene oxide synthase, the enzyme that produces the plant equivalent of prostaglandins (12oxo-phytodienoic acid).

An overview of the lipoxygenase or octadecanoid pathway of plants is shown in Fig. 2. After lipolytic action, the first enzyme in the series is lipoxygenase. Most plant lipoxygenase isoenzymes hydroperoxidize polyunsaturated fatty acids in a stereo-specific manner giving either $13(S)$ - or $9(S)$-hydroperoxides, and some yield a mixture of both. Only a few isoenzymes give a more racemic mixture, similar to fatty acid autoxidation products. Thus, the hydroperoxides usually obtained from linoleic acid are 13(S)-hydroperoxy-cis-9, trans11-octadecadienoic acid (13S-HPOD) and 9(S)-hydroperoxy-trans10, cis-12-octadecadienoic acid (9S-HPOD), and those obtained from linolenic acid are 13(S)-hydroperoxy-cis-9,trans-11,cis-15octadecatrienoic acid (13S-HPOT) and $9(S)$-hydroperoxy-trans-10, cis12,cis-15-octadecatrienoic acid (9S-HPOT). By Fischer convention the 13(S)- and $9(S)$-hydroperoxides are $(L)$ and $(D)$, respectively. After lipoxygenase action, there are several hydroperoxide-metabolizing branches of the pathway that impact the physiology of plants; these aspects are discussed in the sections below.

The jasmonic acid family. The key enzyme involved in the biosynthesis of the family of 7-iso-jasmonic acid, jasmonic acid, their esters, and numerous related metabolites was first observed in flaxseed (Linum usitatissimum L.) to transform 13S-HPOD into 12-oxo-13hydroxy-cis-9-octadecenoic acid ( $\alpha$-ketol).Zimmerman (1966) named this enzyme hydroperoxide isomerase. Subsequently, hydroperoxide isomerase was found in the germ of corn seed (Zea mays L.), and, 


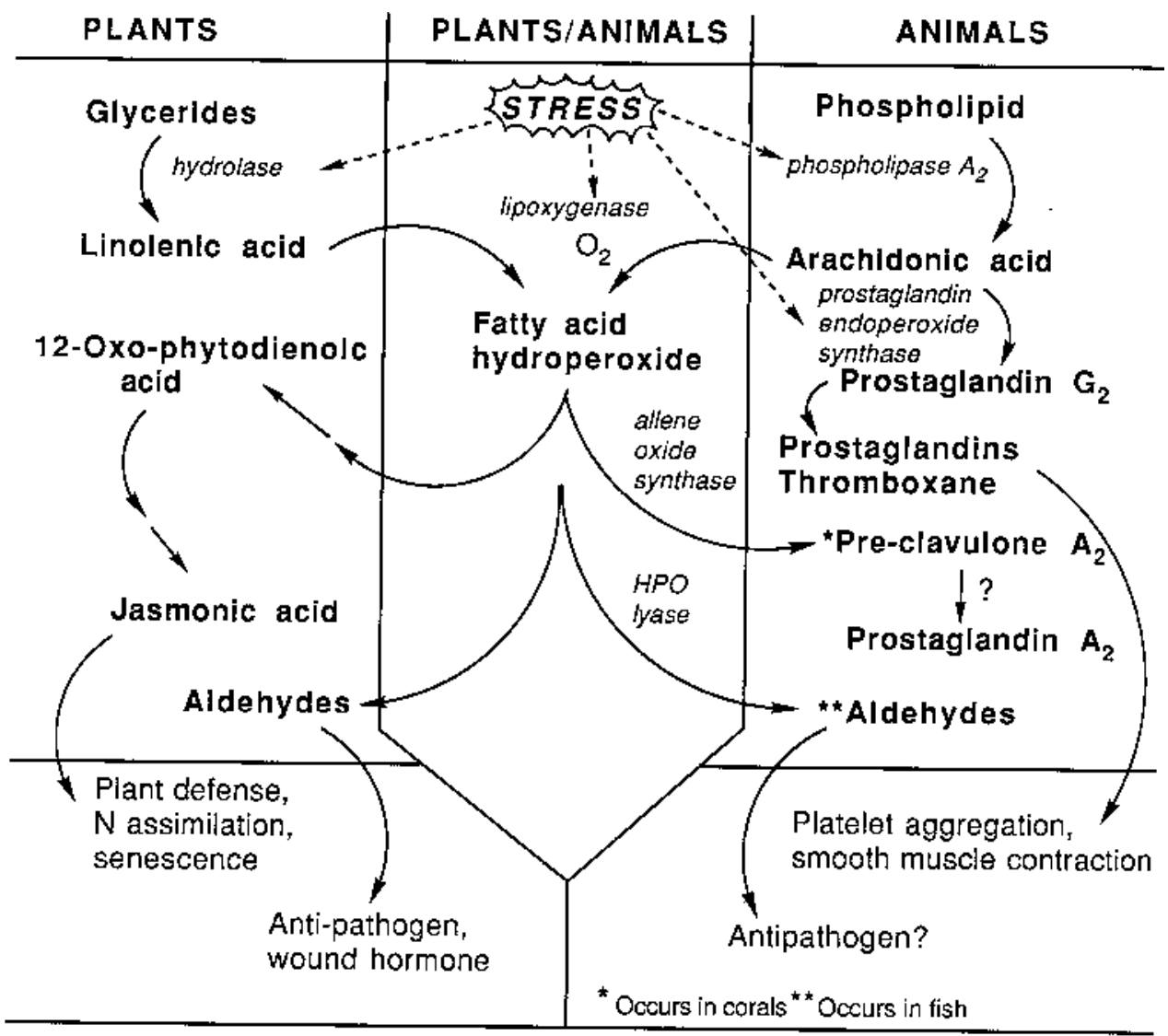

Fig. 1. Model of the stress-activated octadecanoid pathway of plants and eicosanoid pathway of animals showing reactions shared by both, as well as those unique to either the plant or animal kingdom.

\section{GLYCERIDE LIPIDS}

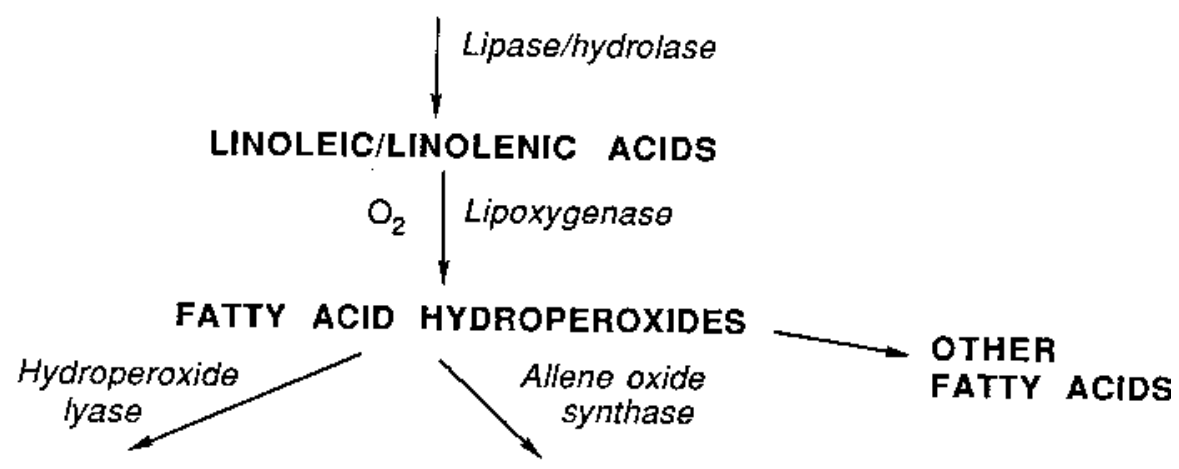

ALDEHYDES/

ALDEHYDE ACIDS

1

OTHER SHORT-

CHAIN METABOLITES

\section{ALLENE OXIDE FATTY ACIDS}

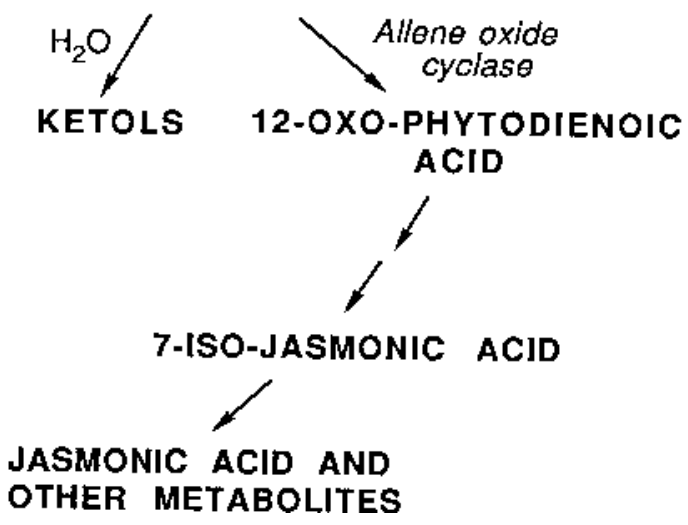

Fig. 2. A summary of the major metabolic branches in the plant octadecanoid pathway. 


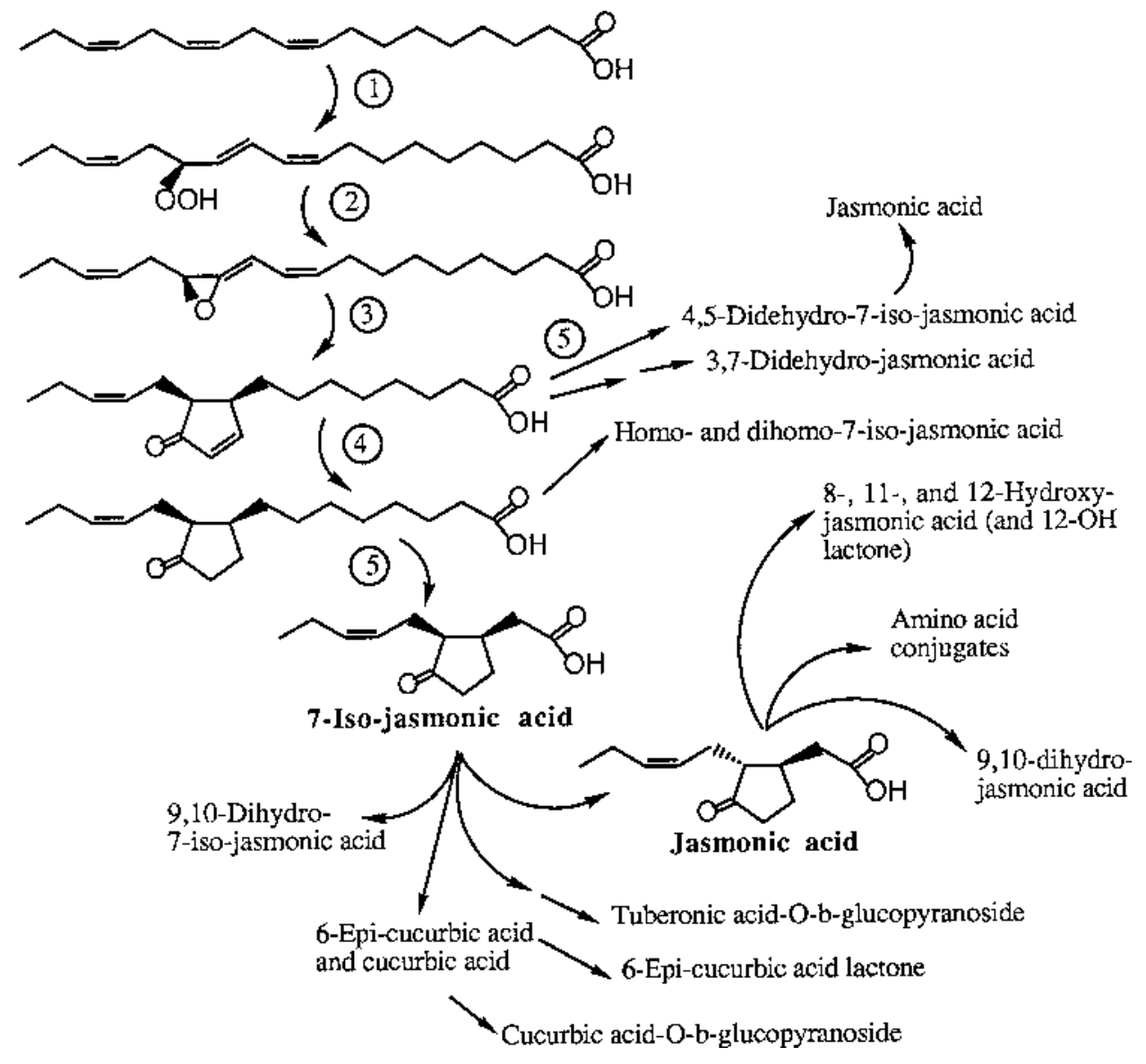

Fig. 3. The sequential conversion of linolenic acid into the jasmonic acid family of phytohormones. The enzymic reactions to 7-iso-jasmonic acid have been established as follows: 1) 13(S)-hydroperoxide-specific lipoxygenase, 2) allene oxide synthase, 3) allene oxide cyclase, 4) 12-oxo-phytodienoic acid reductase, 5 ) three $\beta$-oxidation steps. The other conversions shown have not been directly connected with specific enzymic reactions, but they are logical choices based on known biosynthetic reactions. Not shown are the esters of jasmonic and 7-iso-jasmonic acids; methyl and ethyl esters are known.

additionally, the $\gamma$-ketol, 12-oxo-9-hydroxy-trans-10-octadecenoic acid, was produced from $13 S$-HPOD (Gardner, 1970). The corn germ enzyme also converted 9S-HPOD into the corresponding $\alpha$ - and $\gamma$ ketols. Several years later, Zimmerman and Feng (1978) reported a "new" enzyme, hydroperoxide cyclase, that catalyzed the conversion of $13 S$-HPOT into a cyclic fatty acid, 12-oxo-phytodienoic acid. Subsequently, Hamberg (1987) showed that the $\alpha$ - and $\gamma$-ketols were derived from hydrolysis of the actual enzymic product, an unstable allene oxide fatty acid. He renamed the enzyme as hydroperoxide dehydrase, but this nomenclature was changed again to allene oxide synthase by Song and Brash (1991), who isolated the enzyme and characterized it as a cytochrome $\mathrm{P} 450$. The allene oxide synthase gene from flaxseed was recently cloned and sequenced (Song et al., 1993). Researchers soon recognized that the allene oxide fatty acid was the intermediate involved in cyclization of $13 \mathrm{~S}$-HPOT into 12-oxophytodienoic acid (Fig. 3) (Baertschi et al., 1988; Brash et al., 1988; Hamberg, 1988). Earlier, Corey et al. (1987) had suggested that an analogue of 12-oxo-phytodienoic acid, pre-clavulone A (Fig. 1), was formed in coral via a fatty acid allene oxide intermediate; a suggestion fully confirmed by Brash's group (Brash et al., 1987). In plants, only the $13 S$-HPOT was converted into the cyclic fatty acid; whereas allene oxides from the $9 S$-HPOT, $9 S$-HPOD, and $13 S$-HPOD exclusively underwent hydrolysis to the ketols. Reaction of $13 S$-HPOT catalyzed by allene oxide synthase results in the spontaneous cyclization of the intermediate allene oxide; however, hydrolysis to the ketols occurs to a larger extent. Also, spontaneous cyclization causes the formation of racemic 12-oxo-phytodienoic acid (9S, 13S, and 9R, 13R); but in the presence of another enzyme, allene oxide cyclase, mainly one isomer $(98 \%$ 9S, $13 \mathrm{~S})$ was found in increased yield at the expense of ketol formation (Hamberg and Fahlstadius, 1990).

The next steps in the pathway to jasmonic acid involved the reduction of the double bond of the cyclopentenone ring of 12-oxophytodienoic acid by a reductase (Vick and Zimmerman, 1986), followed by three successive $\beta$-oxidations (Vick and Zimmerman, 1983). As shown in Fig. 3, the immediate biosynthetic product is 7-isojasmonic acid, instead of jasmonic acid. Many derivatives related to jasmonic acid are known (see review in Hamberg and Gardner, 1992). Although the specific routes to these derivatives are unknown, the pathways shown in Fig. 3 were constructed by logical use of known biosynthetic reactions. The methyl ester of jasmonic acid, as well as 7iso-jasmonic acid, are commonly occurring natural derivatives. Investigators have used synthetic methyl jasmonate extensively as a "volatile signal" in physiological research.

The biological activities of the jasmonic acid family are extensive (see recent reviews in Farmer and Ryan, 1992a; Hamberg and Gardner, 1992; Sembdner and Parthier, 1993; Staswick, 1992; van den Berg and Ewing, 1991; Weiler, 1993). Because these reviews are available, the literature from 1992 to present will be emphasized, with only a brief summary given of the earlier research (Table 1). Physiological functions of the jasmonic acid family have been largely researched with a synthetic racemate of methyl jasmonate or jasmonic acid. According to Nishida et al. (1985), synthetic methyl jasmonate tends to be composed of $47.5 \%$ methyl jasmonate (natural), $47.5 \%$ methyl entjasmonate (unnatural), 2.5\% methyl 7-iso-jasmonate (natural), and $2.5 \%$ methyl ent-7-iso-jasmonate (unnatural); thus, it is reasonable to expect that the biological activity of the natural methyl esters may have a lower threshold than reported for synthetic racemates. As reported by Koda et al. (1992), methyl ent-7-iso-jasmonate and methyl entjasmonate had lower activity in some applications, but they equally inhibited the straight growth of oat (Avena sativa L.) coleoptiles, compared to the natural isomers. With some notable exceptions, such as the potato-tuberizing phytohormone, tuberonic acid- $O$ - $\beta$ - 
Table 1. Biological activities of methyl jasmonate, jasmonic acid, and related metabolites.

\begin{tabular}{|c|c|c|}
\hline Type of activity & Occurrence in plant and (tissue) ${ }^{2}$ & Investigators $^{y}$ \\
\hline \multicolumn{3}{|l|}{ Protein induction } \\
\hline Vegetative storage proteins & Soybean (leaves) & Anderson; Fransceschi \& Grimes; Staswick et al. \\
\hline Lipoxygenase & Soybean (leaves) & Bell \& Mullet; Tranbarger et al. \\
\hline Jasmonate-induced proteins & Barley (leaves, seedlings); 26 other species & Weidhase et al.; Mueller-Uri et al.; Hermann et al. \\
\hline Proteinase inhibitors & Tomato, tobacco, alfalfa (plants) & Farmer \& Ryan \\
\hline Napin & Rape (embryo culture) & Wilen et al. \\
\hline Cruciferin & Rape (embryo culture) & Wilen et al. \\
\hline Oil-body proteins & Rape, flaxseed (embryo culture) & Wilen et al. \\
\hline Phenylalanine lyase & Soybean (cell culture) & Gundlach et al. \\
\hline Polyphenol oxidase & Apples (fruit), tulip (bulbs) & Czapski et al.; Saniewski \& Czapski \\
\hline Peroxidase & Barley (leaves), tulip (bulbs) & Weidhase et al.; Saniewski \& Czapski \\
\hline \multicolumn{3}{|l|}{ Protein degradation } \\
\hline Rubisco & Barley (leaves) & Weidhase et al.; Popova \& Vaklinova; Maslenkova et al \\
\hline \multicolumn{3}{|l|}{ Secondary metabolite induction } \\
\hline Flavonoids, alkaloids, others & Eschscholtzia, others (cell culture) & Gundlach et al. \\
\hline Anthocyanin & Soybean (seedlings) & Franceschi \& Grimes \\
\hline Tuberization induction & Potato (tubers) & Koda et al.; Yoshihara et al. \\
\hline \multicolumn{3}{|l|}{ Senescence and growth inhibition } \\
\hline Growth inhibition & Rice, wheat, oat, other (seedling) & Yamane et al.; Miersch et al.; Dathe et al.; others \\
\hline Increased respiration & Barley (seedling) & Popova et al.; Satler \& Thimann \\
\hline Leaf abscission & Ficus superba Miq. (leaves) & Ueda et al. \\
\hline Increased stomatal resistance & Commelina benghalensis L., other (leaves) & Raghavendra \& Reddy; Satler \& Thimann \\
\hline Chlorophyll loss & Barley, oat, other (leaves) & Ueda \& Kato; Miersch et al.; Ueda et al.; others \\
\hline \multicolumn{3}{|l|}{ Other effects } \\
\hline Ethylene stimulation & Tomato, apple (fruit) & Saniewski et al.; Czapski \& Saniewski \\
\hline Germination inhibition & Oat, wheat, other (seed), camellia (pollen) & Corbineau et al.; Yamane et al.; Wilen et al.; others \\
\hline Germination stimulation & Seeds requiring cold stratification & Daletskaya \& Sembdner; Berestetzky et al. \\
\hline Tendril coiling & Bryonia dioica Jacq. (tendrils) & Falkenstein et al. \\
\hline Leaf opening inhibition & Mimosa pudica L. (leaves) & Tsurumi \& Asahi \\
\hline Volatile ester inhibition & Apple (fruit) & Olías et al. \\
\hline Lycopene inhibition & Tomato (fruit) & Saniewski \& Czapski \\
\hline
\end{tabular}

${ }^{2}$ Tobacco, Nicotiana tabacum L.; alfalfa, Medicago sativa L.; rape, Brassica napus L.; apple, Malus sp. and Malus malus cv. Golden Delicious; tulip, Tulipa sp.; Eschscholtzia, Eschscholtzia californica Cham.; wheat, Triticum aestivum L.; camellia, Camellia sinensis L.

${ }^{\mathrm{y}}$ References are not available in Literature Cited. See Hamberg and Gardner (1992) for full citations.

glucopyranoside (Yoshihara et al., 1989), little is known of the biological activity of the various other metabolites of jasmonic acid and 7-iso-jasmonic acid. Another unknown is the fate or function of allene oxide hydrolysis products, the $\alpha$ - and $\gamma$-ketols.

Recent investigations have increasingly indicated that predation by herbivores (wounding), elicitation by fungi (hypersensitive response), or both are signaled by the lipoxygenase pathway, and the defense response to the signal occurs at the transcriptional level. This signal is theorized to be the jasmonic acid (or 7-iso-jasmonic acid) produced via the octadecanoid pathway. A reasonable model has been outlined by Farmer and Ryan (1992a, 1992b), which suggests that either a pathogen or a herbivore signals a receptor in the plasma membrane. According to the model, the receptors cause activation of lipase, and this in turn initiates the octadecanoid pathway to jasmonic acid and gene activation. Thus far, there is limited evidence for the activation of lipase by elicitation. Lipoxygenase's role in the hypersensitive response was demonstrated by a negative elicitor response using a lipoxygenase-null potato (Solanum tuberosum L.) callus culture, compared with a lipoxygenase-positive culture (Vaughn and Lulai, 1992). Mueller et al. (1993) found that adding fungal cell walls to a variety of plant cell cultures resulted in the release of free linolenic acid, and within $1 \mathrm{~h}$, the transient formation of 7-iso-jasmonic acid, as well as 12-oxo-phytodienoic acid. In turn, jasmonic/7-iso-jasmonic acid produced as a result of elicitation induces mRNAs for the production of defensive proteins (Dittrich et al., 1992; Gundlach et al., 1992). These proteins, such as phenylalanine ammonia lyase, 4-coumarate:CoA ligase, and chalcone synthase, stimulated production of defensive secondary metabolites. Other recently reported defensive proteins induced by either jasmonic acid, methyl jasmonate, or their precursors (e.g., 12-oxo-phytodienoic acid) include a Kunitz-type proteinase inhibitor (Yamagishi et al., 1993), tobacco proteinase inhibitor (Rickauer et al., 1992), potato proteinase inhibitor II (Kim et al., 1992; Peña-Cortés et al., 1992), a precursor of leaf thionin (Andresen et al., 1992), and several proteinase inhibitors (Farmer and Ryan, 1992b; Farmer et al., 1992). However, it has been recently questioned if the proteinase inhibitors or other proteins play an important role in protection against fungal attack. According to some workers (Cohen et al., 1993; Schweizer et al., 1993), other factors may be important. It has been amply demonstrated that lipoxygenase activity is induced by either wounding or fungal elicitors (e.g., Croft et al., 1990; Fournier et al., 1993; Hildebrand et al., 1989; Melan et al., 1993). Possibly, increased levels of certain lipoxygenase isozymes are a result of methyl jasmonate (or jasmonic acid) induction, such as observed for a lipoxygenase in soybean (Glycine max L.) (Grimes et al., 1992). The increased expression of lipoxygenase could function simply as a vegetative storage protein (Grimes et al., 1992) or could amplify the signal after pathogen attack.

Similar to induction by elicitors, wounding causes expression of a variety of proteins in a manner similar to the induction of these proteins by either methyl jasmonate, jasmonic acid, or their precursors (Farmer and Ryan, 1992b; Farmer et al., 1992; Hildmann et al., 1992). Wounding caused the transient formation of 7-iso-jasmonic acid, which peaked within 30 min to $2 \mathrm{~h}$ (Albrecht et al., 1993). Creelman et al. (1992) also observed jasmonic acid and methyl jasmonate accumulation after wounding soybean stems. Stimulation of Bryonia dioica Jacq. tendrils by streaking with a wooden stick was sufficient to increase the level of jasmonic acid (Weiler et al., 1993). Although wounding causes transient production of the jasmonic acid family of compounds and they induce proteins at the transcriptional level, surprisingly, gene deletion analysis showed that the induction mechanism of potato proteinase inhibitor II by wounding is different from induction by methyl jasmonate (Kim et al., 1992).

In addition, proteins that have no obvious plant defense function are expressed in the presence of either methyl jasmonate or jasmonic acid. Some serve as vegetative storage proteins, like those found earlier in soybean (Glycine max L.) leaves. Soybean storage proteins act as $\mathrm{N}$ sinks within the leaf before their mobilization during seed development. Recent reports include determination of the sequence of the jasmonate-inducible 23-kD (Andresen et al., 1992) and 60-kD (Becker and Apel, 1992) proteins of barley (Hordeum vulgare L.) and detection of an inducible vegetative storage protein in Arabidopsis thaliana L. (Staswick et al., 1992). In contrast, methyl jasmonate 
caused the decline of certain photosynthetic enzymes. Methyl jasmonate impaired translation of transcripts for the large and small subunits of rubisco as well as several light-harvesting chlorophyll-protein complex apoproteins (Reinbothe et al., 1993a, 1993b). It is tempting to hypothesize that plants use the jasmonic acid phytohormones as a signal to switch normal photosynthetic function of the plant to a defensive mode through $\mathrm{N}$ storage and production of defensive substances. Possibly, they also may control $\mathrm{N}$ assimilate partitioning between vegetative and reproductive tissue.

Other biological effects of methyl jasmonate/jasmonic acid studied recently include ethylene biosynthesis (Chou and Kao, 1992a; Sanz et al., 1993), potato (Solanum tuberosum L.) tuberization (Matsuki et al., 1992), tendril coiling (Weiler et al., 1993), seed germination (Ranjan and Lewak, 1992), leaf senescence (Chou and Kao, 1992b), and onion (Allium cepa L.) bulbing (Nojiri et al., 1992). Gene expression induced by methyl jasmonate has been compared with similar promoters, such as abscisic acid, desiccation, wounding, and sucrose (Lorbeth et al., 1992; Mason et al., 1992; Reinbothe et al., 1992).

The aldehyde pathway. Hydroperoxide lyase is an enzyme that cleaves fatty acid hydroperoxides into two fragments at the position between the hydroperoxide-bearing carbon and the double bond. This cleavage results in aldehydic functions on both sides of the site of cleavage, producing both an alkanal/alkenal and an oxo-acid. Generally, there are hydroperoxide lyases specific for either 9-hydroperoxides of linoleic/linolenic acids or 13-hydroperoxides of linoleic/linolenic acids. Although various hydroperoxide lyase enzymes have not been investigated completely in regard to their stereo-selectivity for hydroperoxide substrates, a few have been identified as being specific for hydroperoxides with the $S$-configuration, but thus far, none has been identified as $R$-specific. Recent reviews outline these pathways in more detail (Gardner, 1989, 1991; Hatanaka et al., 1987).

Hydroperoxide-lyase-catalyzed reactions are commonly observed in plants, particularly in wounded tissues, and they often result in characteristic plant odors. 13-Hydroperoxides of linoleic and linolenic acid cleave into hexanal and cis-3-hexenal, respectively, as well as 12oxo-cis-9-dodecenoic acid (Fig. 4). A hydroperoxide lyase specific for 13-hydroperoxides was recently isolated from tea [Camellia sinensis
(L.) Ktze.] leaves (Matsui et al., 1991). The cis-3-hexenal and 12-oxocis-9-dodecenoic acid are often isomerized by an alkenal isomerase (Phillips et al., 1979) into trans-2-hexenal and 12-oxo-trans-10dodecenoic acid, respectively. Zimmerman and Coudron (1979) showed that the latter oxo-acid is a wound hormone, "traumatin," and this compound is undoubtedly the precursor of "traumatic acid," which English et al. described in 1939. Hexanal has a rancid green odor, whereas cis-3-hexenal and trans-2-hexenal have intense grassy and spicy-green odors, respectively. Alcohol dehydrogenases reduce the aldehydes into the corresponding alcohols (Fig. 4) (Matoba et al., 1989), which lead to similar, more subdued odors. Recently, the pathway has been expanded to include the conversion of cis-3-hexenal into 4-hydroxy-trans-2-hexenal (Gardner and Hamberg, 1993). 4Hydroxy-trans-2-hexenal, as well as the more intensively studied 4hydroxy-trans-2-nonenal, are genotoxic and cytotoxic (reviewed by Esterbauer et al., 1991).

Cleavage of 9-hydroperoxides proceeds by the process described above, except the products are either cis-3-nonenal or cis-3,cis-6nonadienal from the hydroperoxides of linoleic or linolenic acids, respectively, as well as 9-oxononanoic acid (Fig. 5). The 9-hydroperoxide-specific hydroperoxide lyase has been separated from the 13hydroperoxide-specific lyase, indicating that they are individual isoenzymes (Matsui et al., 1989). After formation of the C-9 aldehydes, other transformations occur similar to those discussed above for the aldehydes derived from 13-hydroperoxides (Fig. 5). The odors produced by cleavage of 9-hydroperoxides are principally due to the intense cucumber (Cucumis sativus L.)-like odor of cis-3-nonenal and cis-3,cis-6-nonadienal with a more subdued and altered odor contributed by their corresponding alcohols or trans-2-alkenals.

Another type of hydroperoxide lyase, affording different cleavage fragments from those discussed above, has been reported in fungi, alga, and a species of grass. For example, this hydroperoxide lyase converts $13 S$-HPOD into either pentanol or pentane, as well as 13-oxotrans-11,cis-9-octadecadienoic acid (see review in Gardner, 1991). A particularly interesting reaction of this type is found in mushroom (Psalliota bispora Lange). Apparently, a lipoxygenase may exist that is specific for oxidizing the $10 \mathrm{~S}$-position of fatty acid; that is, mush-

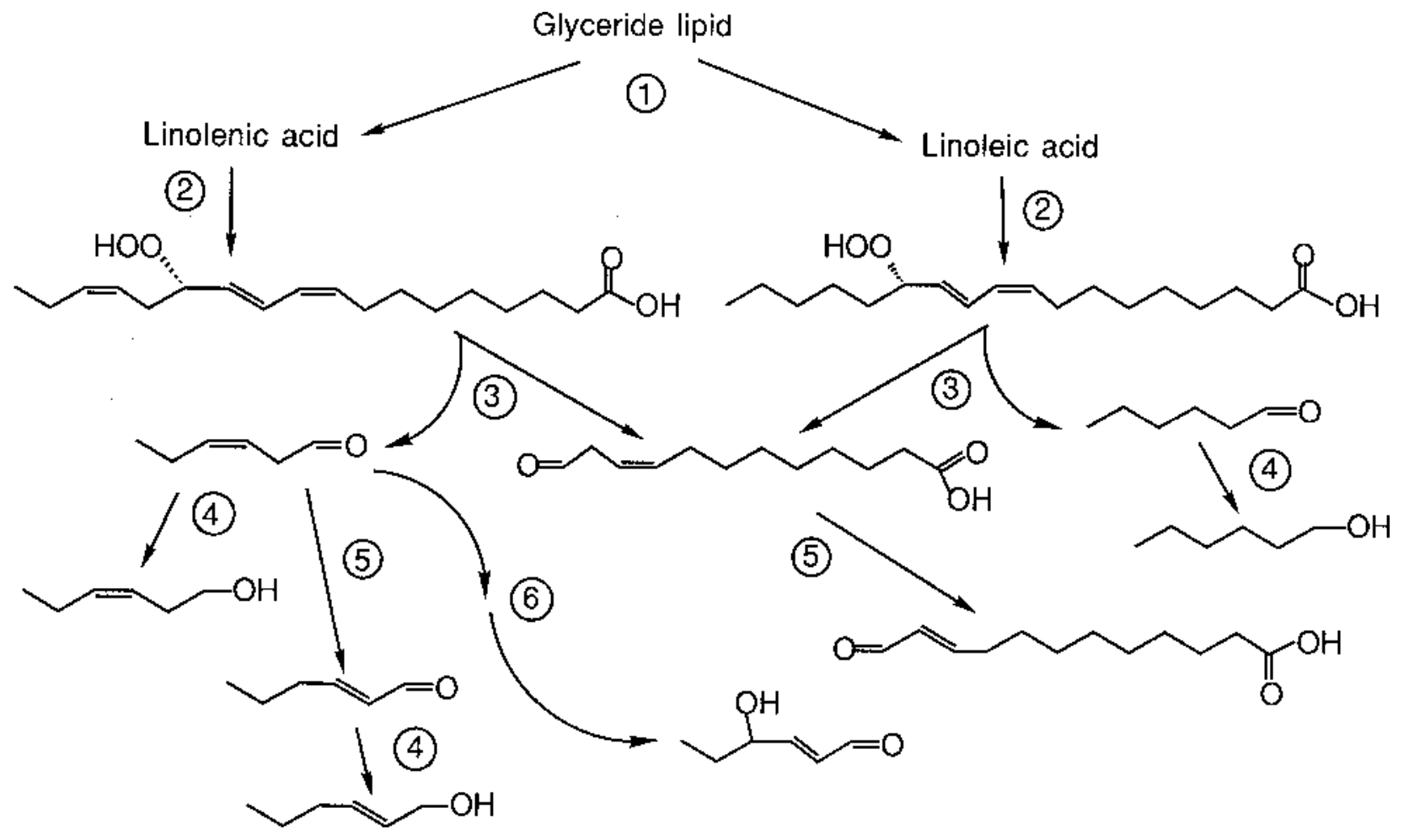

Fig. 4. The $\mathrm{C}_{6}-\mathrm{C}_{12}$ cleavage pathway to aldehydes and alcohols via a 13(S)-hydroperoxide-specific lipoxygenase. The specific enzymes involved are 1) a family of lipolytic enzymes, 2) 13(S)-hydroperoxide-specific lipoxygenase, 3) hydroperoxide lyase, 4) alcohol dehydrogenase, 5) cis-3(9):trans-2(10)-enal isomerase, 6) cis-3-alkenal oxygenase and hydroperoxide epoxygenase. 


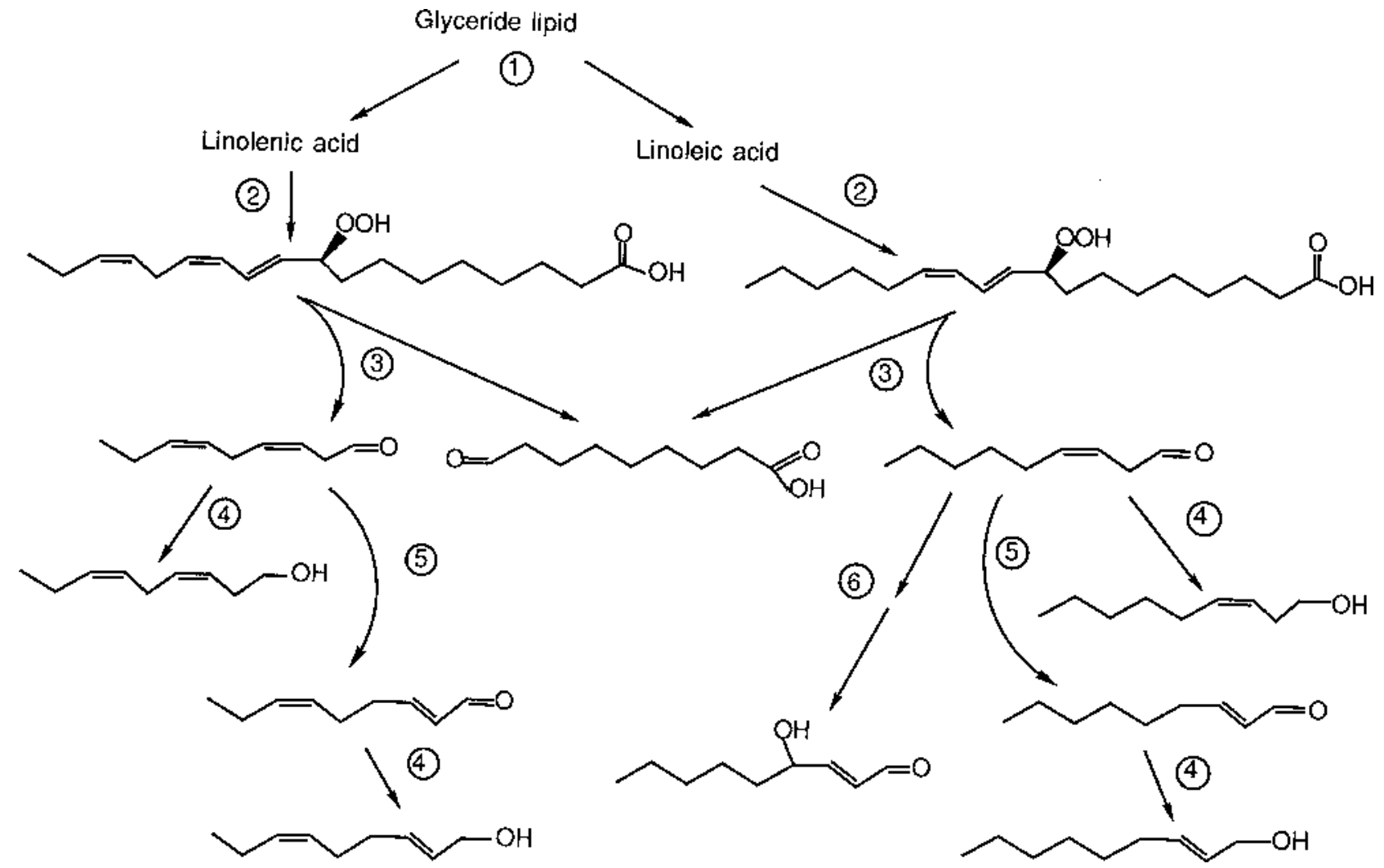

Fig. 5. The $\mathrm{C}_{9}-\mathrm{C}_{9}$ cleavage pathway to aldehydes via a $9(S)$-hydroperoxide-specific lipoxygenase. The specific enzymes are 1) a family of lipolytic enzymes, 2 ) $9(S)$-hydroperoxide-specific lipoxygenase, 3) hydroperoxide lyase, 4) alcohol dehydrogenase, 5) cis-3:trans-2-enal isomerase, 6) cis-3-alkenal oxygenase and hydroperoxide epoxygenase.

room hydroperoxide lyase cleaved the $10 S$-hydroperoxide of linoleic acid into 1-octen-3-ol and 10-oxo-trans-8-decenoic acid(Wurzenberger and Grosch, 1984). 1-Octen-3-ol is an important flavor component of mushrooms.

A role for the aldehydes languished in obscurity for many years after the first reports of physiological activity. Major et al. (1960) and Schildknecht and Rauch (1961) found that trans-2-hexenal was fungitoxic, and Nandi and Fries (1976) found antifungal activity with other hydroperoxide-lyase-derived aldehydes. Subsequently, Zimmerman and Coudron (1979) reported a wound-healing action of 12-oxo-trans-10-dodecenoic acid. More recently, there have been numerous investigations of antifungal and antimicrobial activity of the hydroperoxide-lyase-generated aldehydes, including activity against certain pathogenic strains of these organisms (Bradow, 1991; Croft et al., 1993; Deng et al., 1993; Doehlert et al., 1993; Gardner et al., 1990; Gueldner et al., 1985; Hamilton-Kemp et al., 1992; Urbasch, 1987; Vaughn and Gardner, 1993; Zeringue and McCormick, 1989, 1990). In one particularly interesting study (Croft et al., 1993), Phaseolus vulgaris L. leaves inoculated with an avirulent strain of Pseudomonas syringae pv phaseolicola Burkholder caused a burst of hexenals and hexenols after 15 to $24 \mathrm{~h}$, which corresponds to the time of the hypersensitive response. One of the hexenals, trans-2-hexenal, was particularly inhibitory to the growth of $P$. syringae pv phaseolicola. Because the hexenal/hexenol burst occurred before phytoalexin accumulation, these compounds may be early volatile phytoalexins important to early plant responses. However, a virulent, compatible strain of $P$. syringae pv phaseolicola elicited hexenals/hexenols only at levels slightly above the controls. In addition to antifungal and antimicrobial activity, anti-insect activity has been demonstrated for some of the aldehydes (Chamberlain et al., 1991; Hildebrand et al., personal communication; Mohri et al., 1990).

The fungitoxicity of 4-hydroxy-trans-2-nonenal is comparatively high (Vaughn and Gardner, 1993). In addition to antifungal activity, the 4-hydroxy-alkenals, including 4-hydroxy-trans-2-hexenal, may cause other physiological effects. According to Esterbauer (1992), 4hydroxy-trans-2-nonenal may modulate gene expression. Since 4- hydroxy-trans-2-nonenal and 4-hydroxy-trans-2-hexenal activate phospholipase D, these 4-hydroxy-alkenals also appear to have some control over the generation of second messengers, such as phoshatidic acid and diacylglycerol (Natarajan et al., 1993). At least one enzyme, glucose-6-phosphate dehydrogenase, has been inactivated by exposure to 4-hydroxy-trans-2-nonenal (Szweda et al., 1993).

Other hydroperoxide-decomposing enzymes. Another major pathway of linoleic/linolenic acid hydroperoxide metabolism involves the formation of hydroxy-diene/triene, epoxy-ene/diene, epoxyhydroxyene/diene, and trihydroxy-ene/diene fatty acids. There has been some debate about the relative importance of two possible pathways of formation of these fatty acids. As ascertained in the laboratories of Blée (Blée and Schuber, 1990a, 1990b; Blée et al., 1993) and Hamberg (Hamberg and Fahlstadius, 1992; Hamberg and Hamberg, 1990), one pathway, catalyzed by hydroperoxide-dependent peroxygenase (or epoxygenase), involves the epoxidation of double bonds with peroxide oxygen, resulting in the simultaneous reduction of hydroperoxide to hydroxide. Primary products are epoxy-, epoxyhydroxy-ene/diene, and hydroxy-diene/triene fatty acids. Trihydroxy-ene/diene fatty acids are hydrolysis products of epoxyhydroxy-ene/diene fatty acids. An alternative pathway involves formation of an alkoxyl radical from hydroperoxide and subsequent alkoxyl rearrangement into epoxyhydroxy-ene/diene fatty acids (for a discussion of these two possibilities, see review by Gardner, 1991).

The physiological importance of the various oxygenated fatty acids discussed in the preceding paragraph has been attributed to their antifungal action against rice blast disease (Kato et al., 1983, 1984, 1985, 1986a, 1986b, 1991; Ohta et al., 1990; Shimura et al., 1983). Both lipoxygenase and lipid hydroperoxide-decomposing activities are activated after infection of rice (Oryza sativa L.) with rice blast fungus, especially with an incompatible strain of the fungus (Ohta et al., 1991). In addition, two products of the lipoxygenase and lipid hydroperoxide-decomposing system elicited phytoalexins in Oryza sativa $\mathrm{L}$. (Li et al., 1991). Similarly, a trihydroxy-ene fatty acid is produced by the root of Colocasia esculenta var. antiquorum L. in defense against Ceratocystis fimbriata, the black rot fungus (Masui 
and Kojima, 1990; Masui et al., 1989). And, according to Blée and Schuber (1993), the various fatty acids produced by the hydroperoxide-dependent peroxygenase reaction are cutin monomers and their precursors. The production of a cutin barrier may be yet another important defensive function of the lipoxygenase pathway in plants.

\section{Literature Cited}

Albrecht, T., et al. 1993. Quantification of rapid, transient increases in jasmonic acid in wounded plants using a monoclonal antibody. Planta 191:86-94.

André, É. and K. Hou. 1932. The presence of a lipoid oxidase in soy bean, Glycine soja, Lieb. C.R. Acad. Sci. Paris 194:645-647 (Chem. Abstr. 1932. 26:3004.)

Andresen, I., et al. 1992. The identification of leaf thionin as one of the main jasmonate-induced proteins of barley (Hordeum vulgare). Plant Mol. Biol. 19:193-204.

Baertschi, S.W., C.D. Ingram, T.M. Harris, and A.R. Brash. 1988. Absolute configuration of cis-12-oxophytodienoic acid of flaxseed: Implications for the mechanism of biosynthesis from the 13(S)-hydroperoxide of linolenic acid. Biochemistry 27:18-24.

Becker, W. and K. Apel. 1992. Isolation and characterization of a cDNA clone encoding a novel jasmonate-induced protein of barley (Hordeum vulgare L.). Plant Mol. Biol. 19:1065-1067.

Blée, E. and F. Schuber. 1990a. Stereochemistry of the epoxidation of fatty acids catalyzed by soybean peroxygenase. Biochem. Biophys. Res. Commun. 173:1354-1360.

Blée, E. and F. Schuber. 1990b. Efficient epoxidation of unsaturated fatty acids by a hydroperoxide-dependent oxygenase. J. Biol. Chem. 265:1288712894.

Blée, E. and F. Schuber. 1993. Biosynthesis of cutin monomers: Involvement of a lipoxygenase/peroxygenase pathway. Plant J. 4:113-123.

Blée, E., A.L. Wilcox, L.J. Marnett, and F. Schuber. 1993. Mechanism of reaction of fatty acid hydroperoxides with soybean peroxygenase. J. Biol. Chem. 268:1708-1715.

Bradow, J.M. 1991. Relationship between chemical structure and inhibitory activity of $\mathrm{C}_{6}$ through $\mathrm{C}_{9}$ volatiles emitted by plant residues. J. Chem. Ecol. 17:2193-2212.

Brash, A.R., S.W. Baertschi, C.D. Ingram, and T.M. Harris. 1987. On noncyclooxygenase prostaglandin synthesis in the sea whip coral, Plexaura homomalla: An 8(R)-lipoxygenase pathway leads to formation of an $\alpha$ ketol and a racemic prostanoid. J. Biol. Chem. 262:15829-15839.

Brash, A.R., S.W. Baertschi, C.D. Ingram, and T.M. Harris. 1988. Isolation and characterization of natural allene oxides: Unstable intermediates in the metabolism of lipid hydroperoxides. Proc. Natl. Acad. Sci. USA 85:33823386.

Chamberlain, D.A., G. Wilson, and M.F. Ryan. 1991. trans-2-Nonenal insect repellent, insecticide, and flavor compound in carrot roots, cell suspensions, and "hairy" root cultures. J. Chem. Ecol. 17:615-624.

Chou, M.C. and C.H. Kao. 1992a. Stimulation of 1-aminocyclopropane-1carboxylic acid-dependent ethylene production in detached rice leaves by methyl jasmonate. Plant Sci. 83:137-141.

Chou, M.C. and C.H. Kao. 1992b. Methyl jasmonate, calcium, and leaf senescence in rice. Plant Physiol. 99:1693-1694.

Cohen, Y., U. Gisi, and T. Niderman. 1993. Local and systemic protection against Phytophthora infestans induced in potato and tomato plant by jasmonic acid and jasmonic methyl ester. Phytopathology 83:1054-1062.

Corey, E.J., M. d'Alarcao, S.P.T. Matsuda, and P.T. Lansbury, Jr. 1987. Intermediacy of 8-( $R)$-HPETE in the conversion of arachidonic acid to preclavulone A by Clavularia viridis. Implications for the biosynthesis of marine prostanoids. J. Amer. Chem. Soc. 109:289-290.

Creelman, R.A., M.L. Tierney, and J.E. Mullet. 1992. Jasmonic acid/methyl jasmonate accumulate in wounded soybean hypocotyls and modulate wound gene expression. Proc. Natl. Acad. Sci. USA 89:4938-4941.

Croft, K.P.C., F. Jüttner, and A.J. Slusarenko. 1993. Volatile products of the lipoxygenase pathway evolved from Phaseolus vulgaris (L.) leaves inoculated with Pseudomonas syringae pv phaseolicola. Plant Physiol. 101:1324.

Croft, K.P.C., C.R. Voisey, and A.J. Slusarenko. 1990. Mechanism of hypersensitive cell collapse: Correlation of increased lipoxygenase activity with membrane damage in leaves of Phaseolus vulgaris (L.) inoculated with an avirulent race of Pseudomonas syringae pv. phaseolicola. Physiol. Mol. Plant Pathol. 36:49-62.

Deng, W., et al. 1993. Effects of six-carbon aldehydes and alcohols on bacterial proliferation. J. Agr. Food Chem. 41:506-510.

Dittrich, H., T.M. Kutchan, and M.H.Zenk. 1992. The jasmonate precursor, 12oxo-phytodienoic acid, induces phytoalexin synthesis in Petroselinum crispum cell cultures. FEBS Lett. 309:33-36.

Doehlert, D.C., D.T. Wicklow, and H.W. Gardner. 1993. Evidence implicating the lipoxygenase pathway for providing resistance to soybeans against Aspergillus flavus. Phytopathology 83:1473-1477.

English, J. Jr., J. Bonner, and A.J. Haagen-Smit. 1939. Structure and synthesis of a plant wound hormone. Science 90:329.

Esterbauer, H. 1992. Biochemical aspects. Soc. Free Radical Res. Nwsl. 2(2):5.

Esterbauer, H., R.J. Schaur, and H. Zollner. 1991. Chemistry and biochemistry of 4-hydroxynonenal, malonaldehyde and related aldehydes. Free Radical Biol. Med. 11:81-128.

Farmer, E.E., R.R. Johnson, and C.A. Ryan. 1992. Regulation of expression of proteinase inhibitor genes by methyl jasmonate and jasmonic acid. Plant Physiol. 98:995-1002.

Farmer, E.E. and C.A. Ryan. 1992a. Octadecanoid-derived signals in plants. Trends Cell Biol. 2:236-240.

Farmer, E.E. and C.A. Ryan. 1992b. Octadecanoid precursors of jasmonic acid activate the synthesis of wound-inducible proteinase inhibitors. Plant Cell 4:129-134

Fournier, J., et al. 1993. Purification and characterization of elicitor-induced lipoxygenase in tobacco cells. Plant J. 3:63-70.

Gardner, H.W. 1970. Sequential enzymes of linoleic acid oxidation in corn germ: Lipoxygenase and linoleate hydroperoxide isomerase. J. Lipid Res. 11:311-321.

Gardner, H.W. 1989. How the lipoxygenase pathway affects the organoleptic properties of fresh fruit and vegetables, p. 98-112. In: D.B. Min and T.H. Smouse (eds.). Flavor chemistry of lipid foods. Amer. Oil Chem. Soc., Champaign, Ill.

Gardner, H.W. 1991. Recent investigations into the lipoxygenase pathway of plants. Biochim. Biophys. Acta 1084:221-239.

Gardner, H.W., D.L. Dornbos, Jr., and A.E. Desjardins. 1990. Hexanal, trans2-hexenal, and trans-2-nonenal inhibit soybean, Glycine max, seed germination. J. Agr. Food Chem. 38:1316-1320.

Gardner, H.W. and M. Hamberg. 1993. Oxygenation of 3(Z)-nonenal to (2E)4-hydroxy-2-nonenal in the broad bean (Vicia faba L.). J. Biol. Chem. 268:6971-6977.

Grimes, H.D., D.S. Koetje, and V.R. Franceschi. 1992. Expression, activity, and cellular accumulation of methyl jasmonate-responsive lipoxygenase in soybean seedlings. Plant Physiol. 100:433-443.

Gueldner, R.C., D.M. Wilson, and A.R. Heidt. 1985. Volatile compounds inhibiting Aspergillus flavus. J. Agr. Food Chem. 33:411-413.

Gundlach, H., M.J. Müller, T.M. Kutchan, and M.H.Zenk. 1992. Jasmonic acid is a signal transducer in elicitor-induced plant cell cultures. Proc. Natl. Acad. Sci. USA 89:2389-2393.

Hamberg, M. 1987. Mechanism of corn hydroperoxide isomerase: Detection of 12,13(S)-oxido-9(Z),11-octadecadienoic acid. Biochim. Biophys. Acta 920:76-84

Hamberg, M. 1988. Biosynthesis of 12-oxo-10,15(Z)-phytodienoic acid: Identification of an allene oxide cyclase. Biochem. Biophys. Res. Commun. 156:543-550.

Hamberg, M. and P. Fahlstadius. 1990. Allene oxide cyclase: A new enzyme in plant lipid metabolism. Arch. Biochem. Biophys. 276:518-526.

Hamberg, M. and P. Fahlstadius. 1992. On the specificity of a fatty acid epoxygenase in broad bean (Vicia faba L.). Plant Physiol. 99:987-995.

Hamberg, M. and H.W. Gardner. 1992. Oxylipin pathway to jasmonates: Biochemistry and biological significance. Biochim. Biophys. Acta 1165:118.

Hamberg, M. and G. Hamberg. 1990. Hydroperoxide-dependent epoxidation of unsaturated fatty acids in the broad bean (Vicia faba L.). Arch. Biochem. Biophys. 283:409-416

Hamberg, M. and B. Samuelsson. 1974. Prostaglandin endoperoxides. Novel transformations of arachidonic acid in human platelets. Proc. Natl. Acad. Sci. USA 71:3400-3404.

Hamilton-Kemp, T.R., C.T. McCracken, Jr., J.H. Loughrin, R.A. Andersen, and D.F. Hildebrand. 1992. Effects of some natural volatile compounds on the pathogenic fungi Alternaria alternata and Botrytis cinerea. J. Chem. Ecol. 18:1083-1091.

Hatanaka, A., T. Kajiwara, and J. Sekiya. 1987. Biosynthetic pathway for $\mathrm{C}_{6}$ aldehydes formation from linolenic acid in green leaves. Chem. Phys. Lipids 44:341-361.

Hildebrand, D.F., J.G. Rodriguez, C.S. Legg, G.C. Brown, and G. Bookjans. 1989. The effects of wounding and mite infestation on soybean leaf lipoxygenase levels. Z. Naturforsch. 44c:655-659.

Hildmann, T., et al. 1992. General roles of abscisic and jasmonic acids in gene activation as a result of mechanical wounding. Plant Cell 4:1157-1170.

Kato, T., et al. 1983. Self defensive substances in rice plant against rice blast disease. Tetrahedron Lett. 24:4715-4718.

Kato, T., et al. 1984. Unsaturated hydroxy fatty acids, the self defensive substances in rice plant against rice blast disease. Chem. Lett. p. 409-412.

Kato, T., et al. 1985. Structure and synthesis of unsaturated trihydroxy $\mathrm{C}_{18}$ fatty acids in rice plant suffering from rice blast disease. Tetrahedron Lett. 26:2357-2360. 
Kato, T., et al. 1986a. Structural elucidation of 11-hydroxy-12,13epoxyoctadeca- $(9 Z, 15 Z)$-dienoic acids from rice plants suffering from rice blast disease. J. Chem. Soc. Chem. Commun. p. 743-744.

Kato, T., et al. 1986b. Structure and synthesis of 11,12,13-trihydroxy-9Z,15Zoctadecadienoic acids from rice plant suffering from rice blast disease. Chem. Lett. p. 577-580.

Kato, T., Y. Yamaguchi, T. Hirukawa, and N. Hoshino. 1991. Structural elucidation of naturally occurring 9,12,13-trihydroxy fatty acids by a synthetic study. Agr. Biol. Chem. 55:1349-1357.

Kim, S.-R., J.-L. Choi, M.A. Costa, and G. An. 1992. Identification of G-box sequence as an essential element for methyl jasmonate response of potato proteinase inhibitor II promoter. Plant Physiol. 99:627-631.

Koda, Y., Y. Kikuta, T. Kitahara, T. Nishi, and K. Mori. 1992. Comparison of various biological activities of stereoisomers of methyl jasmonate. Phytochemistry 31:1111-1114.

Li, W.X., O. Kodama, and T. Akatsuka. 1991. Role of oxygenated fatty acids in rice phytoalexin production. Agr. Biol. Chem. 55:1041-1047.

Lorbeth, R., C. Dammann, M. Ebneth, S. Amati, and J.J. Sánchez-Serrano. 1992. Promoter elements involved in environmental and developmental control of potato proteinase inhibitor II expression. Plant J. 2:477-486.

Major, R.T., P. Marchini, and T. Sproston. 1960. Isolation from Ginkgo biloba L. of an inhibitor of fungus growth. J. Biol. Chem. 235:3298-3299.

Mason, H.S., D.B. Dewald, R.A. Creelman, and J.E. Mullet. 1992 . Coregulation of soybean vegetative storage protein gene expression by methyl jasmonate and soluble sugars. Plant Physiol. 98:859-867.

Masui, H. and M. Kojima. 1990. Lipid peroxidation and its role in taro tubers infected by Ceratocystis fimbriata. Agr. Biol. Chem. 54:1689-1695.

Masui, H., T. Kondo, and M. Kojima. 1989. An antifungal compound, 9,12,13trihydroxy-(E)-10-octadecenoic acid, from Colocasia antiquorum inoculated with Ceratocystis fimbriata. Phytochemistry 28:2613-2615.

Matoba, T., et al. 1989. n-Hexanol formation from n-hexanal by enzyme action in soybean extracts. J. Food Sci. 54:1607-1610.

Matsui, K., T. Hiromitu, T. Kajiwara, T. Kakuno, and A. Hatanaka. 1991. Fatty acid hydroperoxide cleaving enzyme, hydroperoxide lyase, from tea leaves. Phytochemistry 30:2109-2113.

Matsui, K., Y. Shibata, T. Kajiwara, and A. Hatanaka. 1989. Separation of $13-$ and 9-hydroperoxide lyase activities in cotyledons of cucumber seedlings. Z. Naturforsch. 44c:883-885.

Matsuki, T., H. Tazaki, T. Fujimori, and T. Hogeisu. 1992. The influences of jasmonic acid methyl ester on microtubules in potato cells and formation of potato tubers. Biosci. Biotechnol. Biochem. 56:1329-1330.

Melan, M.A., et al. 1993. An Arabidopsis thaliana lipoxygenase gene can be induced by pathogens, abscisic acid, and methyl jasmonate. Plant Physiol. 101:441-450.

Mohri, S., Y. Endo, K. Matsuda, K. Kitamura, and K. Fujimoto. 1990. Physiological effects of soybean seed lipoxygenases on insects. Agr. Biol. Chem. 54:2265-2270.

Mueller, M.J., W. Brodschelm, E. Spannagl, and M.H. Zenk. 1993. Signaling in the elicitation process is mediated through the octadecanoid pathway leading to jasmonic acid. Proc. Natl. Acad. Sci. USA 90:7490-7494.

Nandi, B. and N. Fries. 1976. Volatile aldehydes, ketones, esters and terpenoids as preservatives against storage fungi in wheat. Z. Pflanzenkrankh. Pflanzenschutz 83:284-294.

Natarajan, V., W.M. Scribner, and M.M. Taher. 1993. 4-Hydroxynonenal, a metabolite of lipid peroxidation, activates phospholipase D in vascular endothelial cells. Free Radical Biol. Med. 15:365-375.

Nishida, R., T.E. Acree, and H. Fukami. 1985. Optical resolution of methyl jasmonate and methyl epijasmonate. Agr. Biol. Chem. 49:769-772.

Nojiri, H., et al. 1992. Qualitative and quantitative analysis of endogenous jasmonic acid in bulbing and non-bulbing onion plants. Plant Cell Physiol. 33:1225-1231.

Nugteren, D.H., R.K. Beerthuis, and D.A. van Dorp. 1966. The enzymic conversion of all-cis 8,11,14-eicosatrienoic acid into prostaglandin $\mathrm{E}_{1}$. Rec. Trav. Chim. Pays-Bas 85:405-419.

O'Connor, D.E., E.D. Mihelich, and M.C. Coleman. 1984. Stereochemical course of the autoxidative cyclization of lipid hydroperoxides to prostaglandin-like bicyclo endoperoxides. J. Amer. Chem. Soc. 106:3577-3584.

Ohta, H., et al. 1990. The occurrence of lipid hydroperoxide-decomposing activities in rice and the relationship of such activities to the formation of antifungal substances. Plant Cell Physiol. 31:1117-1122.

Ohta, H., et al. 1991. A lipoxygenase pathway is activated in rice after infection with the rice blast fungus Magnaporthe grisea. Plant Physiol. 97:94-98.

Peña-Cortés, H., T. Albrecht, S. Prat, E.W. Weiler, and L. Willmitzer. 1993. Aspirin prevents wound-induced gene expression in tomato leaves by blocking jasmonic acid biosynthesis. Planta 191:123-128.

Peña-Cortés, H., X. Liu, J.S. Serrano, R. Schmid, and L. Willmitzer. 1992. Factors affecting gene expression of patatin and proteinase-inhibitor-II gene families in detached potato leaves: Implications for their co-expression in developing tubers. Planta 186:495-502.
Phillips, D.R., J.A. Matthew, J. Reynolds, and G.R. Fenwick. 1979. Partial purification and properties of a cis-3:trans-2-enal isomerase from cucumber fruit. Phytochemistry 18:401-404.

Ranjan, R. and S. Lewak. 1992. Jasmonic acid promotes germination and lipase activity in nonstratified apple embryos. Physiol. Plant. 86:335-339.

Reinbothe, S., C. Reinbothe, C. Heintzen, C. Seidenbecher, and B. Parthier. 1993a. A methyl jasmonate-induced shift in the length of the 5' untranslated region impairs translation of the plastid $r b c L$ transcript in barley. EMBO J. 12:1505-1512.

Reinbothe, S., C. Reinbothe, J. Lehmann, and B. Parthier. 1992. Differential accumulation of methyl jasmonate-induced mRNAs in response to abscisic acid and desiccation in barley (Hordeum vulgare). Physiol. Plant. 86:4956.

Reinbothe, S., C. Reinbothe, and B. Parthier. 1993b. Methyl jasmonateregulated translation of nuclear-encoded chloroplast proteins in barley (Hordeum vulgare L. cv. Salome). J. Biol. Chem. 268:10606-10611.

Rickauer, M., A. Bottin, and M.-T. Esquerré-Tugayé. 1992. Regulation of proteinase inhibitor production in tobacco cells by fungal elicitors, hormonal factors and methyl jasmonate. Plant Physiol. Biochem. 30:579584.

Sanz, L.C., J.C. Fernández-Maculet, E. Gómez, B. Vioque, and J.M. Olías. 1993. Effect of methyl jasmonate on ethylene biosynthesis and stomatal closure in olive leaves. Phytochemistry 33:285-289.

Schildknecht, H. and G. Rauch. 1961. The chemical nature of "air-borne phytocide" of leafy plants especially of Robinia pseudacacia II. Communication about defensive substances of plants. Z. Naturforsch. 16b:422429.

Schweizer, P., R. Gees, and E. Mösinger. 1993. Effect of jasmonic acid on the interaction of barley (Hordeum vulgare L.) with the powdery mildew Erysiphe graminis f.sp. hordei. Plant Physiol. 102:503-511.

Sembdner, G. and B. Parthier. 1993. The biochemistry and the physiological and molecular actions of jasmonates. Annu. Rev. Plant Physiol. Plant Mol. Biol. 44:569-589.

Shimura, M., et al. 1983. Anti-conidial germination factors induced in the presence of probenazole in infected host leaves. III. Structural elucidation of substances A and C. Agr. Biol. Chem. 47:1983-1989.

Song, W.-C. and A.R. Brash. 1991. Purification of an allene oxide synthase and identification of the enzyme as a cytochrome P-450. Science 253:781-784.

Song, W.-C., C.D. Funk, and A.R. Brash. 1993. Molecular cloning of an allene oxide synthase: A cytochrome P450 specialized for the metabolism of fatty acid hydroperoxides. Proc. Natl. Acad. Sci. USA 90:8519-8523.

Staswick, P.E. 1992. Jasmonate, genes, and fragrant signals. Plant Physiol. 99:804-807.

Staswick, P.E., W. Su, and S.H. Howell. 1992. Methyl jasmonate inhibition of root growth and induction of a leaf protein are decreased in an Arabidopsis thaliana mutant. Proc. Natl. Acad. Sci. USA 89:6837-6840.

Szweda, L.I., K. Uchida, L. Tsai, and E.R. Stadtman. 1993. Inactivation of glucose-6-phosphate dehydrogenase by 4-hydroxy-2-nonenal. J. Biol.Chem. 268:3342-3347.

Urbasch, I. 1987. Transformation of trans-2-hexenal by Botrytis cinerea PERS. as detoxification mechanisms. Z. Naturforsch. 42c:64-68.

van den Berg, J.H. and E.E. Ewing. 1991. Jasmonates and their role in plant growth and development, with special reference to the control of potato tuberization: A review. Amer. Potato J. 68:781-794.

Vaughn, S.F. and H.W. Gardner. 1993. Lipoxygenase-derived aldehydes inhibit fungi pathogenic on soybean. J. Chem. Ecol. 19:2337-2345.

Vaughn, S.F. and E.C. Lulai. 1992. Further evidence that lipoxygenase activity is required for arachidonic acid-elicited hypersensitivity in potato callus cultures. Plant Sci. 84:91-98.

Vick, B.A. and D.C. Zimmerman. 1982. Levels of oxygenated fatty acids in young corn and sunflower plants. Plant Physiol. 69:1103-1108.

Vick, B.A. and D.C. Zimmerman. 1983. The biosynthesis of jasmonic acid: A physiological role for plant lipoxygenase. Biochem. Biophys. Res. Commun. 111:470-477.

Vick, B.A. and D.C. Zimmerman. 1986. Characterization of 12-oxophytodienoic acid reductase in corn. The jasmonic acid pathway. Plant Physiol. 80:202-205.

Weiler, E.W. 1993. Octadecanoid-derived signaling molecules involved in touch perception in a higher plant. Bot. Acta 106:2-4.

Weiler, E.W., et al. 1993. Evidence for the involvement of jasmonates and their octadecanoid precursors in the tendril coiling response of Bryonia dioica. Phytochemistry 32:591-600.

Wurzenberger, M. and W. Grosch. 1984. Stereochemistry of the cleavage of the 10-hydroperoxide isomer of linoleic acid to 1-octen-3-ol by a hydroperoxide lyase from mushrooms (Psalliota bispora). Biochim. Biophys. Acta 795:163-165.

Yamagishi, K., et al. 1993. Jasmonic acid-inducible gene expression of a Kunitz-type proteinase inhibitor in potato tuber disks. Plant Mol. Biol. 21:539-541. 
Yoshihara, T., et al. 1989. Structure of a tuber-inducing stimulus from potato leaves (Solanum tuberosum L.). Agr. Biol. Chem. 53:2835-2837.

Zeringue, Jr., H.J. and S.P. McCormick. 1989. Relationships between cotton leaf-derived volatiles and growth of Aspergillus flavus. J. Amer. Oil Chem. Soc. 66:581-585.

Zeringue, Jr., H.J. and S.P. McCormick. 1990. Aflatoxin production in cultures of Aspergillus flavus incubated in atmospheres containing selected cotton leaf-derived volatiles. Toxicon 28:445-448.
Zimmerman, D.C. 1966. A new product of linoleic acid oxidation by a flaxseed enzyme. Biochem. Biophys. Res. Commun. 23:398-402.

Zimmerman, D.C. and C.A. Coudron. 1979. Identification of traumatin, a wound hormone, as 12-oxo-trans-10-dodecenoic acid. Plant Physiol. 63:536-541.

Zimmerman, D.C. and P. Feng. 1978. Characterization of a prostaglandin-like metabolite of linolenic acid produced by a flaxseed extract. Lipids 13:313-316.

\title{
Peroxidative Activity of Apple Peel in Relation to Development of Poststorage Disorders
}

\author{
Zhanyuan Du and William J. Bramlage \\ Department of Plant and Soil Sciences, University of Massachusetts, Amherst, MA 01003
}

Lipid peroxidation is a factor in the development of plant tissue senescence (Thompson et al., 1991), and in responses to physiological stresses such as chilling (Parkin and Kuo, 1989). Apple (Malus domestica Borkh.) fruit are commonly stored for long periods at low temperature, and during this time a variety of disorders can develop, only some of which appear to be uniquely associated with senescence. Many apple cultivars are chilling sensitive, although several months near $0 \mathrm{C}$ are required for symptoms to develop (Bramlage and Meir, 1990). During this time, both senescence and chilling injury can occur, and an interaction between these conditions could contribute to the development of certain disorders.

Superficial scald develops on the surface of certain apple cultivars following long-term storage near $0 \mathrm{C}$. The scald results from peroxidation of the sesquiterpene $\propto$-farnesene in fruit peel, producing conjugated trienes that presumably perturb membrane lipids under certain conditions, causing disruption, discoloration, and death of surface cells (Anet, 1974; Huelin and Coggiola, 1970a). The disorder is usually controlled by applying the antioxidant diphenylamine (DPA) to fruit before placing them in storage. DPA inhibits the oxidation of $\propto$-farnesene (Huelin and Coggiola, 1970b).

We recently presented evidence that only a portion of the conjugated trienes are positively correlated with scald development, while another portion is negatively correlated with it (Du and Bramlage, 1993), and that ethylene is fundamentally involved in development of conditions that help determine scald development (Du and Bramlage, 1994). Ethylene production is mediated by free radicals (Gardner and Newton, 1987), and ethylene regulates many aspects of fruit ripening and senescence (Abeles et al., 1992). Also, DPA treatment affects ethylene production, respiration, and enzyme activity (Baker, 1963; Lurie et al., 1989), as well as reducing $\propto$-farnesene oxidation in apple peel. Since lipid peroxidation is a prominent factor in apple senescence (Feys, 1985; Feys et al., 1980), we proposed that lipid peroxidation products may contribute to conditions that determine scald development, and possibly to symptom expression itself. To investigate this hypothesis, we sampled apple fruit under a variety of conditions related to scald development, and assayed them for some general peroxidation products, and for activities of enzymes that are important in controlling the accumulation of peroxidation products in plant tissues. We now detail this work as part of this workshop.

\section{Plant materials}

Investigations occurred over 3 years using fruit grown under normal orchard conditions at the Univ. of Massachusetts Horticultural Research Center, Belchertown.

The cost of publishing this paper was defrayed in part by the payment of page charges. Under postal regulations, this paper therefore must be hereby marked advertisement solely to indicate this fact.
On 26 Sept. and 10 Oct. 1990, $\approx 200$ 'Cortland' and 'Delicious' apples, respectively, were harvested from each of three single-tree replications at commercial maturity. Before storage, half of the harvested fruit of each cultivar was dipped in fungicide [ $227 \mathrm{~g}$ of $50 \%$ methyl 1-(butyl carbamoyl)-2-benzimidazocarbamate (benlate) and $454 \mathrm{~g}$ of $3 \mathrm{a}, 4,7,7 \mathrm{a}$-tetrahydro-2-[(trichloromethyl)thiol]-1- $H$-isoindole1,3(2H)-dione (captan) per 400 liters of water] as control, and the other half was dipped in $2 \mathrm{~g}$ DPA/liter plus fungicide. All fruit then were stored at $0 \mathrm{C}$ in air. Ten-fruit samples were taken from each replicate at harvest and at every 4 weeks during storage, up to a maximum of 16 weeks. Sampled fruit were peeled, and the peel was cut into small pieces, mixed, frozen immediately in dry ice, and stored at $-25 \mathrm{C}$ for subsequent analyses. Scald incidence on the remaining fruit was evaluated visually after 16 weeks at $0 \mathrm{C}$ plus 7 days at 20C. No scald had developed on 'Delicious' at this time, so fruit were returned to storage for an additional 8 weeks plus 7 days at 20C for a second scald evaluation.

On 30 Sept. 1991, $\approx 400$ 'Empire' fruit were harvested from each of four single-tree replications and stored at $0 \mathrm{C}$ in air for 24 weeks. Tenfruit samples were taken at 4-week intervals, peeled, and frozen for analyses as described above. After 24 weeks at $0 \mathrm{C}$, senescent breakdown was present in some fruit. Ten fruit with the disorder and 10 fruit free of it were selected from each replication. Peel was taken from disorder-free fruit as above, but diseased fruit peel was taken only from areas with symptoms. Peel was frozen for assay as above.

On 9 Sept. 1992, $\approx 200$ 'Cortland' fruit were harvested from each of four single-tree replications and stored at $0 \mathrm{C}$ for 20 weeks. Stored fruit then were transferred to $20 \mathrm{C}$ for 7 days and evaluated for scald development. Fruit within each replication then were sorted into three groups according to their scald intensity, i.e., no scald; $1 \%$ to $33 \%$ of fruit surface; and $>33 \%$ of fruit surface affected with scald. Ten fruit without senescent breakdown were selected randomly from each group, peeled, and frozen for analyses.

\section{Assays of lipid peroxidation products}

Extraction. Ten grams of frozen peel were homogenized in a blender with $50 \mathrm{ml}$ of cold acetone for $3 \mathrm{~min}$ and filtered through Whatman no. 4 paper. The filtrate was brought to $75 \mathrm{ml}$ with water and kept at $4 \mathrm{C}$ under refrigeration for measurements.

Measurements. Two groups of products of lipid peroxidation were measured in the present study. The thiobarbituric acid-reactive substances (TBARS) were measured using the thiobarbituric acid assay modified to adjust for the high sugar content of fruit [expressed as nmoles of malondialdehyde (MDA) per gram of fresh weight; Du and Bramlage (1992)]. Total peroxides were determined according to Brennan and Frenkel (1977), modified as follows: $1 \mathrm{ml}$ of properly diluted extract and $4 \mathrm{ml}$ of water were added to $1 \mathrm{ml}$ of titanium reagent ( $20 \%$ titanic tetrachloride in concentrated $\mathrm{HCl}, \mathrm{v} / \mathrm{v})$. After mixing and 
standing for $5 \mathrm{~min}$, the absorbance was measured at $415 \mathrm{~nm}$ against a blank that contained all components except the extract. A standard curve was made from commercial hydrogen peroxide $\left(\mathrm{H}_{2} \mathrm{O}_{2}\right)$, and it gave good linearity for concentrations $<2 \mathrm{~mm}$. The total peroxides were expressed as nmoles of $\mathrm{H}_{2} \mathrm{O}_{2}$ per gram of fresh weight.

\section{Assays of enzyme activities}

Extraction. Two grams of frozen tissue was ground with a mortar and pestle in $10 \mathrm{ml}$ of $50 \mathrm{~mm}$ phosphate buffer (containing $0.2 \%$ insoluble polyvinylpyrrolidone, $0.1 \mathrm{~mm}$ EDTA, and $3 \mathrm{mM} \mathrm{MgCl}_{2 ;} \mathrm{pH}$ 7.0), and a small amount of washed sand. The homogenate was centrifuged at $15,000 \times g$ for $15 \mathrm{~min}$, and the supernatant obtained was used for assays of enzyme activities. Extract preparation was carried out at 0 to 4 C. Enzyme activities were expressed as units per gram of fresh weight.

Assay of catalase. Catalase activity was assayed by the ability to decompose $\mathrm{H}_{2} \mathrm{O}_{2}$. Four milliliters of assay mixture ( $50 \mathrm{~mm}$ Tris buffer, pH 6.8, containing $5 \mathrm{~mm} \mathrm{H}_{2} \mathrm{O}_{2}$ ) was added to $0.5 \mathrm{ml}$ of extract. After $10 \mathrm{~min}$ at $20 \mathrm{C}$, the reaction was stopped by adding $0.5 \mathrm{ml}$ of titanium reagent, as described above. The resulting solution was appropriately diluted and the residual $\mathrm{H}_{2} \mathrm{O}_{2}$ was determined as described above for total peroxides. A control, in which the enzyme activity was stopped at "zero" time, was run at the same time. One unit of catalase activity is defined as the amount of enzyme that decomposed $0.01 \mu \mathrm{mol}$ of $\mathrm{H}_{2} \mathrm{O}_{2}$ per minute under the assay conditions.

Assays of peroxidase (POD) and polyphenoloxidase (PPO). POD and PPO activities were assayed essentially according to Kar and Mishra (1976). One unit of activity of POD or PPO is defined as the amount of the enzyme that caused an increase of 0.1 in the absorbance at $420 \mathrm{~nm}$ by the purpurogallin formed in the assay.

Assays of superoxide dismutase (SOD). SOD activity was measured according to Beauchamp and Fridovich (1971) and Dhindsa et al. (1981) by measuring the ability of SOD to inhibit the photochemical reduction of nitro blue tetrazolium (NBT). The assay mixture contained $50 \mathrm{~mm}$ phosphate buffer ( $\mathrm{pH} 7.8$ ), $13 \mathrm{~mm}$ methionine, $75 \mu \mathrm{M}$ NBT, $2 \mu \mathrm{M}$ riboflavin, $0.1 \mathrm{~mm}$ EDTA, and $100 \mu \mathrm{l}$ of enzyme extract. Three milliliters of the assay mixture in uniform, transparent tubes was shaken and placed $50 \mathrm{~cm}$ below a lightbank consisting of eight $15-\mathrm{W}$ fluorescent lamps. The reaction was started by switching on the lights and was allowed to proceed for $10 \mathrm{~min}$. The reaction then was stopped by switching off the lights, and the absorbance by the assay mixture at $560 \mathrm{~nm}$ was read. The diffuse room light had no measurable effect. The nonirradiated assay mixture did not develop color and served as control, and the assay mixture lacking enzyme extract developed maximum color, which decreased with increasing amount of extract added. One unit of SOD activity is defined as the amount of enzyme that inhibited the NBT photoreduction by $50 \%$ under the assay conditions. However, the percent inhibition was not linear with SOD concentration. Thus, units of SOD activity were calculated from transformed data as described by Asada et al. (1974) and Giannopolitis and Ries (1977). SOD units per milliliter $=(\mathrm{Vo} / \mathrm{V}-1) \times($ dilution factor), where Vo is the slope of the change in absorbance in the absence, and V in the presence, of enzyme extract. The transformation resulted in a linear correlation between the SOD activity and the amount of the extract used in this study $[\mathrm{Vo} / \mathrm{V}=0.989+0.48(\mu \mathrm{l}), \mathrm{R}$ $\left.=0.951^{* * *}\right]$.

Data were subjected to analyses of variance. Least significant difference or Duncan's new multiple range test was used to separate means when applicable.

\section{Findings}

Peroxidative characteristics in fruit peel during storage at $0 \mathrm{C}$ were compared among three apple cultivars with different scald susceptibilities (Table 1). 'Cortland' and 'Delicious' are scald susceptible, while 'Empire' is scald resistant. 'Empire' fruit peel accumulated significantly more TBARS and peroxides during storage than did either 'Cortland' or 'Delicious' fruit peel, and 'Delicious' accumulated somewhat higher concentrations than did 'Cortland'. 'Empire' peel exhibited lower catalase, POD, and PPO activities than that of the
Table 1. Comparisons among cultivars of lipid peroxidation products and enzyme activities in apple peel and development of superficial scald after storage. $^{2}$

\begin{tabular}{lccr}
\hline \hline & \multicolumn{3}{c}{ Cultivar } \\
\cline { 2 - 4 } Measurement & Cortland & Delicious & Empire \\
\hline TBARS (nmol.g ${ }^{-1}$ fresh wt) & $55 \mathrm{a}^{\mathrm{x}}$ & $79 \mathrm{~b}$ & $102 \mathrm{c}$ \\
Peroxides (nmol.g ${ }^{-1}$ fresh wt) & $20 \mathrm{a}$ & $24 \mathrm{~b}$ & $31 \mathrm{c}$ \\
Catalase (unit/g fresh wt) & $58 \mathrm{~b}$ & $58 \mathrm{~b}$ & $56 \mathrm{a}$ \\
POD (unit/g fresh wt) & $53 \mathrm{c}$ & $25 \mathrm{~b}$ & $15 \mathrm{a}$ \\
Total SOD (unit/g fresh wt) & $248 \mathrm{c}$ & $51 \mathrm{a}$ & $157 \mathrm{~b}$ \\
PPO (unit/g fresh wt) & $18 \mathrm{~b}$ & $21 \mathrm{~b}$ & $10 \mathrm{a}$ \\
Scald (\%) & $23 \mathrm{~b}$ & $20 \mathrm{~b}^{\mathrm{w}}$ & $0 \mathrm{a}$ \\
\hline
\end{tabular}

${ }^{26}$ Cortland' and 'Delicious' were harvested on 26 Sept. and 10 Oct. 1990, respectively, and stored for 16 weeks at $0 \mathrm{C}$. 'Empire' was harvested on $27 \mathrm{Sept}$. 1991 and stored for 24 weeks at 0C. Each cultivar was sampled at 4-week intervals and data are means of all sample times.

${ }^{\mathrm{T}} \mathrm{TBARS}=$ thiobarbituric acid-reactive substances; $\mathrm{POD}=$ peroxidase $; \mathrm{SOD}=$ superoxide dismutase; $\mathrm{PPO}=$ polyphenoloxidase.

'Mean separation within rows by Duncan's new multiple range test, $P \leq 0.05$. w'Delicious' did not scald following 16 weeks at $0 \mathrm{C}$ and was returned to storage for an additional 6 weeks. Scald developed during subsequent 7 days at 20C.
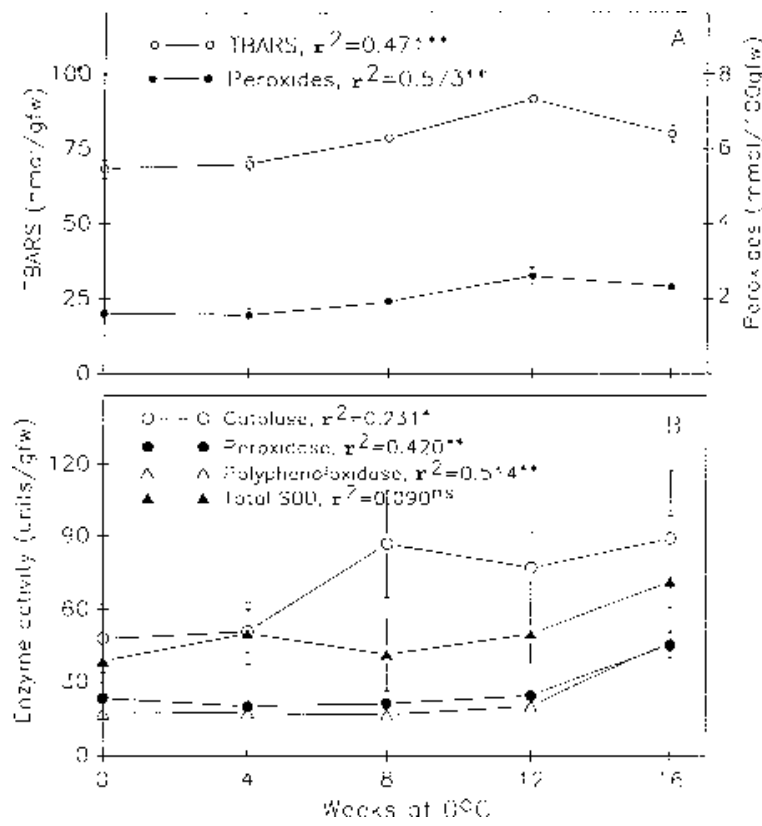

Fig. 1. Changes in (A) concentrations of peroxidation products and in (B) activities of certain enzymes in 'Delicious' apple peel during storage at 0 C. Ns, *,**Nonsignificant or significant at $P \leq 0.05$ or 0.01 , respectively, for linear regressions over time.

Table 2. Effects of diphenylamine (DPA) applied at $2 \mathrm{~g} \cdot \mathrm{liter}^{-1}$ before storage on accumulation of peroxidation products, enzyme activity, and superficial scald development on apples after storage. ${ }^{z}$

\begin{tabular}{|c|c|c|c|c|c|c|}
\hline \multirow[b]{2}{*}{ Measurement ${ }^{y}$} & \multicolumn{3}{|c|}{ Cortland } & \multicolumn{3}{|c|}{ Delicious } \\
\hline & -DPA & & $+\mathrm{DPA}$ & -DPA & & $+\mathrm{DPA}$ \\
\hline TBARS (nmol. $\cdot \mathrm{g}^{-1}$ fresh wt) & 55 & NS & 54 & 78 & NS & 80 \\
\hline Peroxides $\left(\mathrm{nmol} \cdot \mathrm{g}^{-1}\right.$ fresh wt) & 22 & $* *$ & 17 & 24 & $*$ & 20 \\
\hline Catalase (unit/g fresh wt) & 83 & ** & 39 & 70 & ** & 45 \\
\hline POD (unit/g fresh wt) & 55 & NS & 32 & 27 & $*$ & 22 \\
\hline Total SOD (unit/g fresh wt) & 248 & NS & 267 & 51 & NS & 45 \\
\hline $\mathrm{PPO}$ (unit/g fresh wt) & 18 & NS & 18 & 24 & $*$ & 18 \\
\hline Scald $(\%)$ & 20 & $* *$ & 1 & 20 & $* \mathrm{x}$ & 5 \\
\hline
\end{tabular}

${ }^{2}$ Cortland' and 'Delicious' were harvested on 26 Sept. and 10 Oct., respectively, and stored for 16 weeks at $0 \mathrm{C}$. Fruit were sampled every 4 weeks, and data are the means of all sample times.

${ }^{\mathrm{T}} \mathrm{TBARS}=$ thiobarbituric acid-reactive substances; $\mathrm{POD}=$ peroxidase $; \mathrm{SOD}=$ superoxide dismutase; $\mathrm{PPO}=$ polyphenoloxidase.

${ }^{x}$ Scald did not develop on 'Delicious' after 16 weeks at $0 \mathrm{C}$. Fruit were returned to $0 \mathrm{C}$ for an additional 6 weeks, and scald developed during the subsequent 7 days at 20C.

Ns, ${ }^{*, * *}$ Nonsignificant or significant at $P \leq 0.05$ or 0.01 , respectively. Significance of DPA treatment effect for a cultivar and measurement. 
other cultivars, and 'Empire' and 'Delicious' peel had lower SOD activity than did that of 'Cortland'. Despite the indications of higher peroxidative activity in 'Empire' peel during storage, these fruit developed no scald after storage, while the disorder occurred on the other two cultivars.

During storage of 'Delicious' at 0C, slow but significant linear increases in TBARS and peroxides occurred over time (Fig. 1). Catalase, POD, and PPO activities also increased significantly over time, but SOD activity did not change significantly (Fig. 1). Similar results were recorded for 'Cortland', except that SOD activity declined $75 \%$ during 16 weeks at $0 \mathrm{C}$ (data not shown). In 'Empire', only TBARS and catalase increased significantly during storage, while SOD activity decreased slowly (data not shown).

DPA applied before storage slightly reduced peroxide concentrations in peel of both 'Cortland' and 'Delicious' apples during storage but had no effect on TBARS concentrations (Table 2). DPA also markedly reduced catalase activity in both cultivars, slightly reduced POD and PPO activities in 'Delicious', but had no effect on SOD activity in either cultivar. Treatment reduced scald development in both cultivars.

'Cortland' apples at 20C developed no scald, but after 24 weeks of storage at $0 \mathrm{C}$, about one-third of the fruit had developed the disorder (Table 3). At 20C, TBARS and peroxides were higher after 1 week than at harvest, but after 2 weeks, they were at the same levels as at harvest. This transient increase is associated with the onset of ripening (Du, 1993), but it was not accompanied by significant changes in activity of any of the measured enzymes. At $0 \mathrm{C}$, no significant change in either TBARS or peroxides was evident after 12 or 24 weeks, while catalase and POD activities increased during storage. Overall, temperature had no significant effect on peroxidative characteristics other than inducing higher POD activity at $0 \mathrm{C}$ than at $20 \mathrm{C}$.

Peel from 'Cortland' apples with different amounts of superficial scald on their surfaces had similar peroxidative activity after storage for 20 weeks at 0C (Table 4). There was no significant difference in peroxidative activity of peel between scald-free and scalded fruit.

During storage of 'Empire' apples, some fruit developed symptoms of senescent breakdown: soft, brown areas with dark vascular strands developing just beneath the peel, primarily near the calyx end of the fruit. When peel from above these areas ("senescent") was compared with peel from disorder-free fruit ("healthy"), marked differences in peroxidative activity were evident (Fig. 2). Senescent tissue contained much higher concentrations of TBARS and peroxides, and higher activities of catalase, POD, and SOD, but there was no difference in PPO activity.

\section{Implications}

During storage of 'Delicious' apples at 0C, concentrations of TBARS and peroxides gradually increased (Fig. 1), and peroxidation products also increased in 'Cortland' and 'Empire' (data not shown). Since temperature had no significant effect on TBARS or peroxides (Table 3), the increases in apples during storage apparently reflected effects of fruit senescence and were not the result of chilling damage. The suggestion that lipid breakdown results from some combination of chilling and senescence (Parkin et al., 1989) also appears unlikely.

Since plant tissues possess complex systems that control buildup of oxidation products (Winston, 1990), these assays gave limited insight into cellular processes. Catalase, POD, and SOD activities were assayed to see if substantial changes occurred in protecting tissues from peroxide accumulation. Catalase activity increased substantially in fruit peel during storage (Table 3, Fig. 1); the only indications of a marked loss of protection were a $75 \%$ reduction in SOD activity in 'Cortland' peel during 16 weeks at $0 \mathrm{C}$ (data not shown), and a possible reduction of SOD activity in 'Empire' (Table 3). Nevertheless, the TBARS and peroxide data suggest that control systems in apple peel largely kept peroxidative activities in check during prolonged storage of the fruit, and that overall changes were remarkably slow.

Superficial scald is induced soon after harvest, but its symptoms are not expressed until fruit have remained in storage for 3 or more months (Bramlage and Meir, 1990). During this extended storage time, conjugated trienes usually increase in fruit peel, and scald development is positively correlated with maximum conjugated triene concentration (Huelin and Coggiola, 1968). Our hypothesis was that lipid peroxidation products in tissue increase over time, to a point where they contribute to development of scald symptoms. No general relationship existed between scald susceptibility and concentration of peroxidation prod-

Table 3. Effects of temperature on accumulation of lipid peroxidation products, enzyme activity, and superficial scald development on 'Cortland' apples.

\begin{tabular}{|c|c|c|c|c|c|c|c|}
\hline \multirow{2}{*}{$\begin{array}{l}\text { Time of } \\
\text { measurement }\end{array}$} & \multirow{2}{*}{ 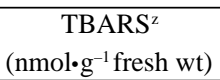 } & \multirow{2}{*}{$\begin{array}{c}\text { Peroxides } \\
\left(\mathrm{nmol} \cdot \mathrm{g}^{-1} \text { fresh wt) }\right.\end{array}$} & Catalase & $\mathrm{POD}^{2}$ & Total SOD ${ }^{z}$ & $\mathrm{PPO}^{2}$ & \multirow{2}{*}{$\begin{array}{c}\text { Scald } \\
(\%)\end{array}$} \\
\hline & & & \multicolumn{4}{|c|}{ (units/g fresh wt) } & \\
\hline At harvest & 53 & 19 & 29 & 41 & 155 & 25 & --- \\
\hline 20C, 1 week & 75 & 27 & 51 & 37 & 108 & 23 & -- \\
\hline $20 \mathrm{C}, 2$ weeks & 51 & 19 & 65 & 40 & 100 & 22 & $2^{y}$ \\
\hline OC, 12 weeks & 52 & 20 & 58 & 54 & 98 & 23 & --- \\
\hline 0C, 24 weeks & 52 & 17 & 77 & 60 & 68 & 27 & 34 \\
\hline $\mathrm{LSD}_{0.05}$ & 20 & 8 & 48 & 14 & 89 & 9 & 16 \\
\hline $0 \mathrm{C}$ vs. $20 \mathrm{C}$ & $\mathrm{NS}^{\mathrm{x}}$ & NS & NS & $*$ & NS & NS & $* * *$ \\
\hline
\end{tabular}

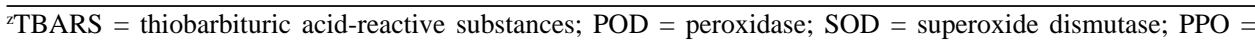
polyphenoloxidase.

${ }^{y}$ Slight scald-like symptoms were present on a few fruit at harvest, but did not become more prevalent during the postharvest period.

${ }^{x}$ This comparison indicates only the main effects of temperature.

Ns, ***** Nonsignificant or significant at $P \leq 0.05$ or 0.001 , respectively.

Table 4. Concentrations of lipid peroxidation products and activities of certain enzymes in 'Cortland' apple peel affected with different intensities of superficial scald. ${ }^{\mathrm{z}}$

\begin{tabular}{|c|c|c|c|c|c|c|}
\hline $\begin{array}{l}\text { Surface } \\
\text { affected } \\
\text { with scald }\end{array}$ & TBARS & Peroxides & Catalase & POD $^{y}$ & Total SOD & $\mathrm{PPO}^{y}$ \\
\hline$(\%)$ & $\left(\mathrm{nmol}^{\circ} \mathrm{g}^{-1}\right.$ fresh wt) & $\left(\mathrm{nmol}^{\circ} \mathrm{g}^{-1}\right.$ fresh wt $)$ & \multicolumn{4}{|c|}{ (units/g fresh wt) } \\
\hline None & 62 & 22 & 35 & 27 & 36 & $\overline{11}$ \\
\hline 1 to 33 & 57 & 22 & 21 & 24 & 40 & 12 \\
\hline 34 to 100 & 55 & 22 & 21 & 26 & 35 & 12 \\
\hline Significance & NS & NS & NS & NS & NS & NS \\
\hline
\end{tabular}

${ }^{2}$ Fruit were harvested on 9 Sept. 1992, and stored at 0C for 20 weeks, plus 1 week at 20C.

yTBARS = thiobarbituric acid-reactive substances; $\mathrm{POD}=$ peroxidase; $\mathrm{SOD}=$ superoxide dismutase; $\mathrm{PPO}=$ polyphenoloxidase.

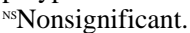



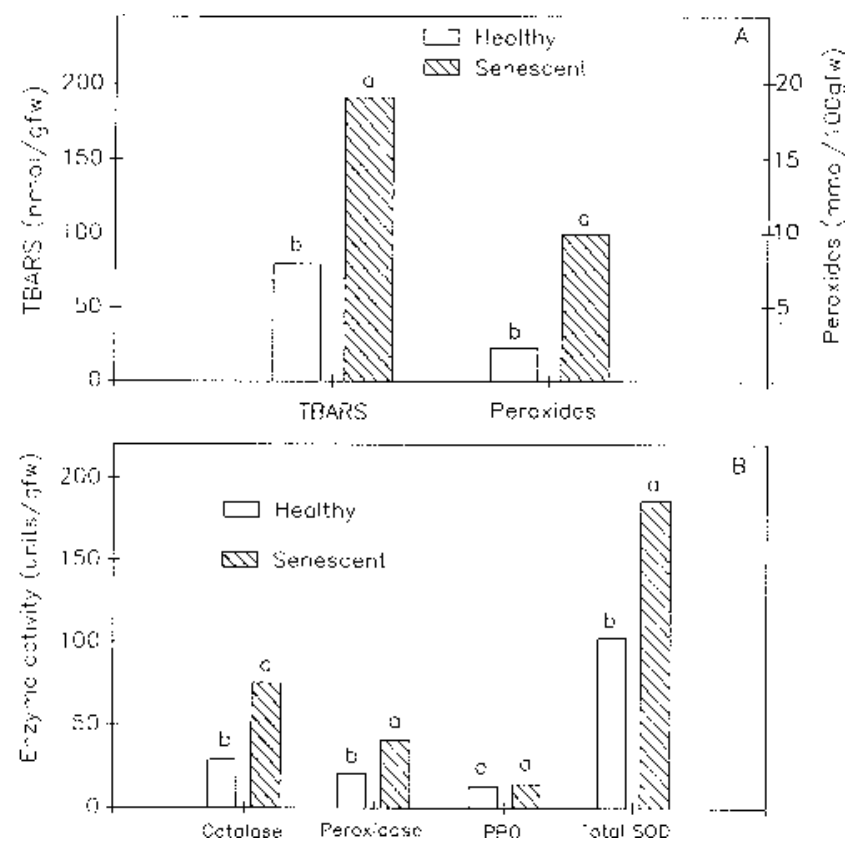

Fig. 2. Comparisons of concentrations of lipid peroxidation products and enzyme activities between peel of 'Empire' apples above areas with senescent breakdown ("senescent") and peel from fruit free of senescent breakdown ("healthy") after storage at 0C for 24 weeks. Mean separation within pairs at $P \leq 0.05$.

ucts. Scald-resistant 'Empire' apples contained higher TBARS and peroxide concentrations than scald-susceptible 'Cortland' and 'Delicious' (Table 1). In addition, there was no difference in TBARS or peroxide concentrations in 'Cortland' at scald-inducing and noninducing temperatures (Table 3 ), and no sudden increase occurred as 'Cortland' apples became liable to scald development at removal from storage (data not shown). However, the increase in peroxidation products (Fig. 1) may have been associated with the increase of conjugated trienes (Huelin and Coggiola, 1968), or with changes in cellular conditions that result in symptom development.

When the lipid-soluble antioxidant DPA was applied to apples at harvest, it reduced the peroxide concentration in apple peel during storage, despite reducing catalase and peroxidase activities (Table 2). This might have resulted from significantly reduced ethylene production (Du and Bramlage, 1994), but it also may indicate that DPA significantly supplemented the endogenous antioxidant concentrations in the peel. Barden and Bramlage (1994b) found that watersoluble antioxidants in apple peel decreased during fruit storage, and that among different lots of fruit, differences in lipid-soluble antioxidants at harvest usually persisted as levels increased during storage. These at-harvest differences among fruit lots were negatively correlated with scald development (Barden and Bramlage, 1994a). Applied DPA may reduce scald by contributing directly, as a lipid-soluble antioxidant, to cellular resistance to initiation of scald symptoms, perhaps by inhibiting fruit senescence (Lurie et al., 1989) or $\propto$ farnesene oxidation to conjugated trienes (Huelin and Coggiola, 1970a).

Our results provide no insight into events during scald symptom development. Tissue with different levels of symptom expression contained TBARS and peroxide concentrations equal to those in scald-free tissue, and equal enzyme activities (Table 4). PPO activity was equal in peel regardless of symptom development (Table 4), and no difference existed in PPO activity among cultivars (Table 1) or between temperatures (Table 3). Lurie et al. (1989) suggested that DPA may reduce scald symptom development by maintaining low PPO activity. We found only slight increases of PPO activity during fruit senescence (Fig. 1), and slight reduction of PPO by DPA (Table 2).

Peel over tissue with senescent breakdown had markedly different peroxidative characteristics than that from breakdown-free fruit
(Fig. 2). These results also suggest that development of scald symptoms is distinct from general cell breakdown and discoloration.

In summary, our work provides no evidence that marked changes in peroxidative activity of apple peel are related to scald development in apples. However, it does not preclude the possibility that lipid peroxidation is related to scald development in more subtle ways, especially in the susceptibility of cell membranes to perturbation by conjugated trienes, which may produce cellular disorganization and symptom expression.

\section{Literature Cited}

Abeles, F.B., P.W. Morgan, and M.E. Saltveit, Jr. 1992. Ethylene in plant biology. 2nd ed. Academic, San Diego.

Anet, E.F.L.J. 1974. Superficial scald, a functional disorder of stored apples. XI. Apple antioxidants. J. Sci. Food Agr. 25:299-304.

Asada, K., M. Takahashi, and M. Nagate. 1974. Assay and inhibitors of spinach superoxide dismutase. Agr. Biol. Chem. 38:471-473.

Baker, J. 1963. Diphenylamine inhibition of electron transport in plant mitochondria. Arch. Biochem. Biophys. 103:148-155.

Barden, C.L. and W.J. Bramlage. 1994a. Separating the effects of low temperature, ripening, and light on loss of scald susceptibility in apples before harvest. J. Amer. Soc. Hort. Sci. 119:54-58.

Barden, C.L. and W.J. Bramlage. 1994b. Relationships of antioxidants in apple peel to changes in $\propto$-farnesene and conjugated trienes during storage, and to superficial scald development after storage. Postharvest Biol. Technol. 4:23-33.

Beauchamp, C. and I. Fridovich. 1971. Superoxide dismutase: Improved assay and an assay applicable to polyacrylamide gel. Anal. Biochem. 44:276287.

Bramlage, W.J. and S. Meir. 1990. Chilling injury of crops of temperate origin, p. 37-49. In: C.Y. Wang (ed.). Chilling injury of horticultural crops, CRC, Boca Raton, Fla.

Brennan, T. and C. Frenkel. 1977. Involvement of hydrogen peroxide in the regulation of senescence in pear. Plant Physiol. 59:411-416.

Dhindsa, R.S., P. Plumb-Dhindsa, and T.A. Thorpe. 1981. Leaf senescence correlated with increased levels of membrane permeability and lipid peroxidation, and decreased levels of superoxide dismutase and catalase. J. Expt. Bot. 32:93-101.

$\mathrm{Du}, \mathrm{Z}$. 1993. Investigation of peroxidation-associated processes involved in senescence and superficial scald of apples (Malus domestica Borkh.). PhD Diss., Univ. of Massachusetts, Amherst.

Du, Z. and W.J. Bramlage. 1992. Modified thiobarbituric acid assay for measuring lipid oxidation in sugar-rich plant tissue extract. J. Agr. Food Chem. 40:1556-1570.

Du, Z. and W.J. Bramlage. 1993. A modified hypothesis on the role of conjugated trienes in superficial scald development on stored apple. J. Amer. Soc. Hort. Sci. 118:807-813.

$\mathrm{Du}, \mathrm{Z}$. and W.J. Bramlage. 1994. Roles of ethylene in the development of superficial scald in 'Cortland' apples. J. Amer. Soc. Hort. Sci. 119:516523.

Feys, M. 1985. Ripening and senescence of fruits: The accumulation of fermentation products and the oxidation of membrane lipids in relation to storage and physiological deterioration of apples. Katholieke Universiteit te Leuven. p. 142-293.

Feys, M., W. Nasens, P. Tobback, and E. Maes. 1980. Lipoxygenase activity in apples in relation to storage and physiological disorders. Phytochemistry 19:1007-1011.

Gardner, H.W. and J.W. Newton. 1987. Lipid hydroperoxides in the conversion of 1-aminocyclopropane-1-carboxylic acid to ethylene. Phytochemistry 26:421-426.

Giannopolitis, C.N. and S.K. Ries. 1977. Superoxide dismutases. 1. Occurrences in higher plants. Plant Physiol. 59:309-314.

Huelin, F.E. and I.M. Coggiola. 1968. Superficial scald, a functional disorder of stored apples. IV. Effect of variety, maturity, oiled wraps, and diphenylamine on concentration of $\propto$-farnesene in the fruit. J. Sci. Food Agr. 19:297-301.

Huelin, F.E. and I.M. Coggiola. 1970a. Superficial scald, a functional disorder of stored apples. VII. Effects of applied farnesene, temperature, and diphenylamine on scald and the concentration and oxidation of $\propto$-farnesene in the fruit. J. Sci. Food Agr. 21:584-589.

Huelin, F.E. and I.M. Coggiola. 1970b. Superficial scald, a functional disorder of stored apples. V. Oxidation of $\propto$-farnesene and its inhibition by diphenylamine. J. Sci. Food Agr. 21:44-48.

Kar, M. and D. Mishra. 1976. Catalase, peroxidase, and polyphenoloxidase activities during rice leaf senescence. Plant Physiol. $57: 315-319$. 
Lurie, S., J. Klein, and R. Ben-Arie. 1989. Physiological changes in diphenylamine-treated 'Granny Smith' apples. Israel J. Bot. 38:199-207.

Parkin, K.L. and S.J. Kuo. 1989. Chilling-induced lipid degradation in cucumber (Cucumis sativa L. cv Hybrid C) fruit. Plant Physiol. 90:1049-1056.

Parkin, K.L., A. Marangoni, R.L. Jackman, R.Y. Yada, and D.W. Stanley. 1989. Chilling injury, a review of possible mechanisms. J. Food Biochem. 13:127-153.

Thompson, J.E., J.H. Brown, G. Paliyath, J.F. Todd, and K. Yao. 1991.
Membrane phospholipid catabolism primes the production of activated oxygen in senescing tissues, p. 57-66. In: E.J. Pell and K.L. Steffen (eds.). Active oxygen/oxidative stress and plant metabolism. Amer. Soc. Plant Physiol., Rockville, Md.

Winston, G.W. 1990. Physiological basis for free radical formation in cells: Production and defenses, p. 57-86. In: R.G. Alscher and J.R. Cumming (eds.). Stress responses in plant: Adaptation and acclimation mechanisms. Wiley-Liss, New York.

\title{
Release of Fluorescent Peroxidized Lipids from Membranes in Senescing Tissue by Blebbing of Lipid- Protein Particles
}

\author{
Katalin Hudak, Kening Yao, and J.E. Thompson \\ Department of Biology, University of Waterloo, Waterloo, Ont. N2L 3G1, Canada
}

\begin{abstract}
Several lines of evidence indicate that peroxidation of membrane lipids is an inherent feature of ripening and senescence of plant tissues. Dhindsa and Dhindsa (1981), for example, demonstrated a correlation between lipid peroxidation and increased membrane permeability in senescing leaves. Levels of $\mathrm{H}_{2} \mathrm{O}_{2}$ and lipid hydroperoxides also increase in ripening fruit, and Frenkel (1978) has reported that ripening can be delayed by inhibiting the formation of $\mathrm{H}_{2} \mathrm{O}_{2}$. Pear (Pyrus communis L. var. Bartlett) and banana (Musa cavendishii L. var. Valery) fruit contain fluorescent products of lipid peroxidation that increase during natural or ethylene-induced ripening (Maguire and Haard, 1975). Senescing leaves and cotyledons also accumulate fluorescent peroxidation products (Wilhelm and Wilhelnova, 1981), and evidence shows that they are localized in membrane lipid bilayers (Pauls and Thompson, 1984).
\end{abstract}

Fluorescent peroxidized lipids are a family of compounds with a characteristic Schiff base structure $(-\mathrm{N}=\mathrm{C}-\mathrm{C}=\mathrm{C}-\mathrm{N})$ that is formed by the reaction of aldehydes from peroxidized lipids with free amino groups (Tappel, 1975). Schiff bases formed from malondialdehyde and amino compounds have characteristic fluorescence spectra that feature an excitation maximum at $\approx 360 \mathrm{~nm}$ and an emission maximum at $\approx 430 \mathrm{~nm}$ (Fig. 1), and are thus similar to the lipofuscins known to accumulate in animal tissues during aging (Tappel, 1975). Fluorescent peroxidized lipids appear to be formed in membrane bilayers (Pauls and Thompson, 1984), and if they were to accumulate therein, they could be expected to disrupt membrane structural integrity. Indeed, the accumulation of peroxidized lipids in senescing membranes may contribute to loss of membrane function as tissues age (Thompson et al., 1987).

In this report, we describe evidence indicating that fluorescent peroxidized lipids are released from membranes by blebbing (pinching of surface protrusions) of lipid-protein particles from the membrane surface. The data presented have been obtained from studies with senescing bean (Phaseolus vulgaris L.) cotyledons grown under etiolation conditions and senescing carnation (Dianthus caryophyllus L.) flower petals. These lipid-protein particles have been partially characterized previously (Yao and Thompson, 1993; Yao et al., 1991a, 1991b, 1993a), are present in plant and animal tissue (Yao et al., 1991a, 1993b), and have been tentatively termed deteriosomes to denote their putative role in removing lipid and protein catabolites from membranes (Yao et al., 1991a). Lipid and protein catabolism is a normal feature of membrane turnover, and any significant accumulation of these catabolites in the bilayer could have a disruptive effect on membrane structure. Recent evidence suggests that these catabolites

The cost of publishing this paper was defrayed in part by the payment of page charges. Under postal regulations, this paper therefore must be hereby marked advertisement solely to indicate this fact. are selectively removed by blebbing of lipid-protein particles from the membrane surface (Yao and Thompson, 1993; Yao et al., 1991a, 1991b, 1993a). Impairment of this blebbing process with advancing senescence appears to result in an accumulation of lipid catabolites in senescing membranes that causes bilayer destabilization and loss of membrane function (Yao et al., 1991b).

\section{Peroxidized lipid accumulation in senescing membranes}

Fluorescence spectra of lipid extracts from microsomal membranes of cotyledons at various stages of senescence all show excitation maxima at $370 \mathrm{~nm}$ and emission maxima at $430 \mathrm{~nm}$ (Fig. 1). The

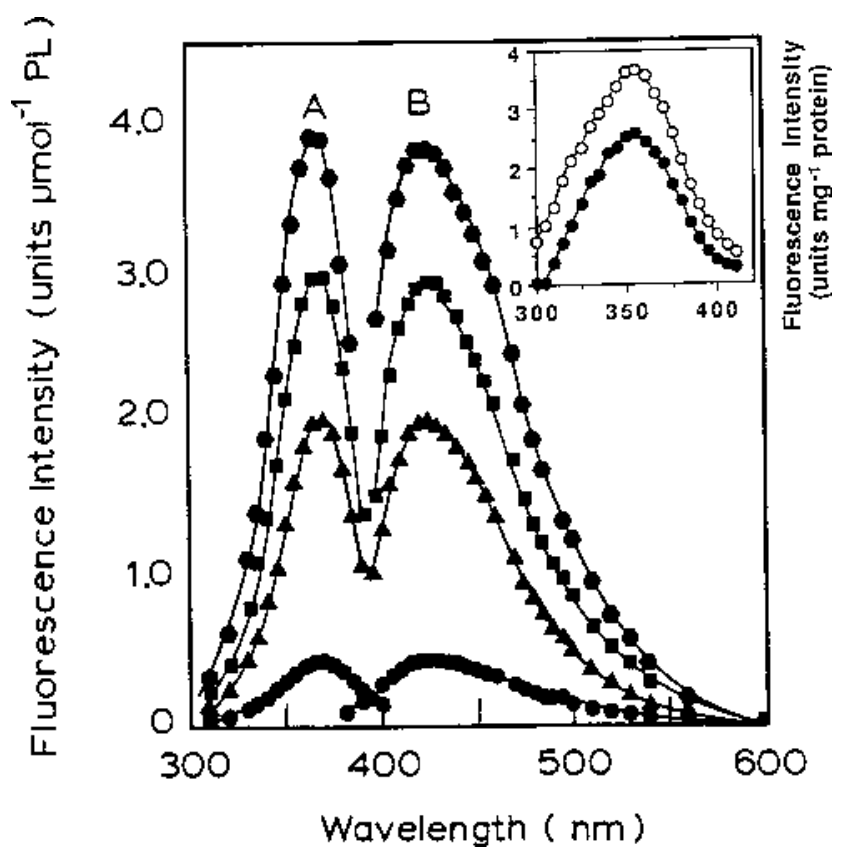

Fig. 1. Excitation (A) and emission (B) spectra for lipid extracts of microsomal membranes isolated from senescing bean cotyledons (age in days). (†) young, 2 days old; ( $\mathbf{\Delta}) 4 ;(\mathbf{\square}) 7$; (solid hexagon ) 9 . At 4 days, the cotyledons are beginning to show visible manifestations of senescence, and by 9 days, they are extensively senescent (data are from Pauls and Thompson, 1984). Inset: corresponding excitation spectra for lipid extracts of microsomal membranes from the petals of carnation flowers. (-) Young, stage 2 flowers (petals fully expanded and flowers fully open with yellow-tinted centers); $(\bigcirc)$ senescing stage 4 flowers (petals showing pronounced inrolling). 
intensity of fluorescence in the membrane lipid extracts expressed on a per micromole phospholipid basis increases about 10 -fold between day 2, when the tissue is young, and day 9, when the tissue is extensively senescent (Fig. 1). Similar data have been obtained for microsomal membranes isolated from the petals of senescing carnation flowers (inset of Fig. 1). Fluorescent compounds of this type have also increased in ripening fruit (Maguire and Haard, 1975) and in the chloroplasts of senescing leaves (Wilhelm and Wilhelnova, 1981).

\section{Localization of fluorescent peroxidized lipids in the cytosol}

Fluorescent peroxidized lipids also are present in the cytosol (postmicrosomal supernatant) of senescing tissues (Table 1). Indeed, for 2-day-old bean cotyledon tissue, $\approx 59 \%$ of the total (microsomal plus cytosol) fluorescence-reflecting peroxidized lipids is in the cytosol, and $\approx 41 \%$ is associated with the microsomal membranes. As the tissue ages, however, there is a pronounced accumulation of peroxidized lipids in membranes such that $\approx 72 \%$ of the total (microsomal plus cytosol) fluorescence is associated with the microsomal fraction and only $\approx 28 \%$ with the cytosol (Table 1 ). In absolute terms, this represents about a 2 -fold increase with advancing senescence in levels of fluorescent peroxidized lipids in microsomal membranes and a $52 \%$ decline in cytosolic levels of fluorescent peroxidized lipids. Thin-layer chromatography has indicated that the major fluorescing products in the membranes are peroxidized phospholipids, whereas the cytosol contains peroxidized phospholipids and peroxidized free fatty acids (Yao et al., 1993a).

Further fractionation of the cytosol revealed that, for young and senescing tissue, $\approx 50 \%$ of the cytosolic fluorescent peroxidized lipids are associated with nonsedimentable lipid-protein particles (Table 1, Fig. 2). These lipid-protein particles appear to be formed by blebbing from membranes and are isolated by centrifuging the cytosol (postmicrosomal supernatant) at $250,000 \times g$ for $12 \mathrm{~h}$ to sediment residual membrane, and then filtering the resulting supernatant through a 300,000-Da cutoff filter to yield nonsedimentable lipid-protein particles in the retentate and particle-free cytosol in the filtrate (Yao et al., 1991a, 1991b). When these particles are further purified by gel filtration, the lipid and protein co-elute, which indicates that they are associated in a macromolecular complex (Yao and Thompson, 1993; Yao et al., 1991a). The particles are spherical (Yao et al., 1991a) (Fig. 3A), have a propensity to bleb into smaller particles (Fig. 3A), and range from 50 to $250 \mathrm{~nm}$ in diameter (Fig. 3B). Their protein composition is complex and clearly distinguishable from those of corresponding microsomal membranes and particle-free cytosol (Fig. 4). These particles contain phospholipids but are enriched in phospholipid catabolites, in particular free fatty acids and gel-phase-forming lipids (Yao et al., 1991b). Indeed, the free : esterified fatty acid ratio is typically 6- to 10-fold higher in nonsedimentable lipid-protein particles than in corresponding membranes.

These observations have prompted the proposal that these lipidprotein particles serve as a vehicle for removing destabilizing molecular catabolites from membranes, and the particles have been tentatively termed "deteriosomes" to connote this putative function (Yao and Thompson, 1993; Yao et al., 1991a, 1991b). This proposal is reinforced by the finding that the lipid-protein particles contain fluorescent peroxidized lipids as well (Fig. 2). Indeed, the level of

Table 1. Fluorescence of lipid extracts from microsomal membranes, cytosol, lipid-protein particles, and particle-free cytosol isolated from young 2-dayold and senescing 7-day-old bean cotyledons.

\begin{tabular}{lcc}
\hline \hline & \multicolumn{2}{c}{ Percentage of total fluorescence } \\
\cline { 2 - 3 } Fractions & $\begin{array}{c}\text { 2-day-old } \\
\text { cotyledons }\end{array}$ & $\begin{array}{c}\text { 7-day-old } \\
\text { cotyledons }\end{array}$ \\
\hline Microsomal membranes & $41.6 \pm 4.6$ & $71.9 \pm 10.9$ \\
Cytosol & $58.4 \pm 6.4$ & $28.1 \pm 4.2$ \\
Lipid-protein particles & $26.4 \pm 1.2$ & $14.3 \pm 2.3$ \\
Particle-free cytosol & $32.0 \pm 1.7$ & $13.8 \pm 4.7$ \\
\hline
\end{tabular}

${ }^{2}$ Total fluorescence is the sum of microsomal membrane plus cytosolic fluorescence and is based on $10 \mathrm{~g}$ of cotyledon tissue. Fluorescence emission was recorded at $430 \mathrm{~nm}$ (excitation $360 \mathrm{~nm}$ ). Standard errors of the means are indicated; $\mathrm{n}=3$. Data are from Yao et al. (1993a).
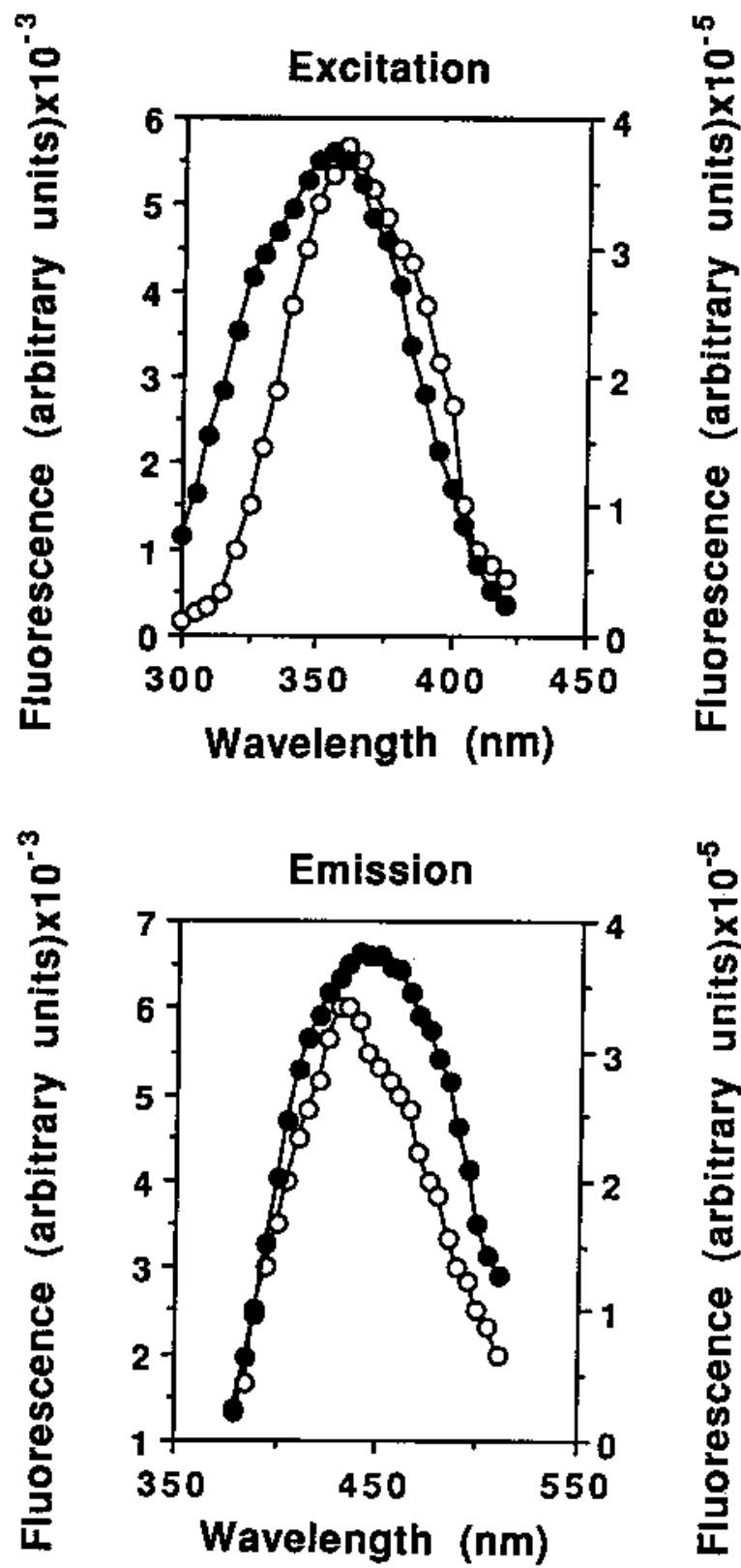

Fiğ 2. Exंcitation and emission specträ fờ lipid extracts" of nonsedimentable lipid-protein particles. (O) Lipid-protein particles from young, 2-day-old bean cotyledon tissue; (-) lipid-protein particles from petals of young, stage 2 carnation flowers. The cotyledon data are from Yao et al. (1993a).

peroxidized lipids relative to phospholipid is about 15 -fold higher in the lipid-protein particles than in microsomal membranes. The peroxidized lipids are also detectable in the particle-free cytosol of young and senescing tissue (Table 1), which may reflect either breakdown of the lipid-protein particles upon release into the cytosol, or partitioning of the fluorescent peroxidized lipids from the lipidprotein particles into the cytosol.

Earlier studies have indicated that the formation of nonsedimentable lipid-protein particles is a two-step process involving phospholipid catabolism, which is enzymatically mediated and gives rise to bilayer-destabilizing lipid catabolites, followed by blebbing from the membrane surface (Yao et al., 1991a, 1991b). This contention is based on the findings that nonsedimentable lipid-protein particles with essentially similar properties can be formed in vitro from isolated membranes under conditions in which phospholipid catabolism is activated, and that their formation can be prevented by heat denaturation of the membranes (Yao et al., 1991a). In particular, nonsedimentable lipid-protein particles formed from isolated membranes under in vitro conditions are also enriched in phospholipid catabolites, specifi- 

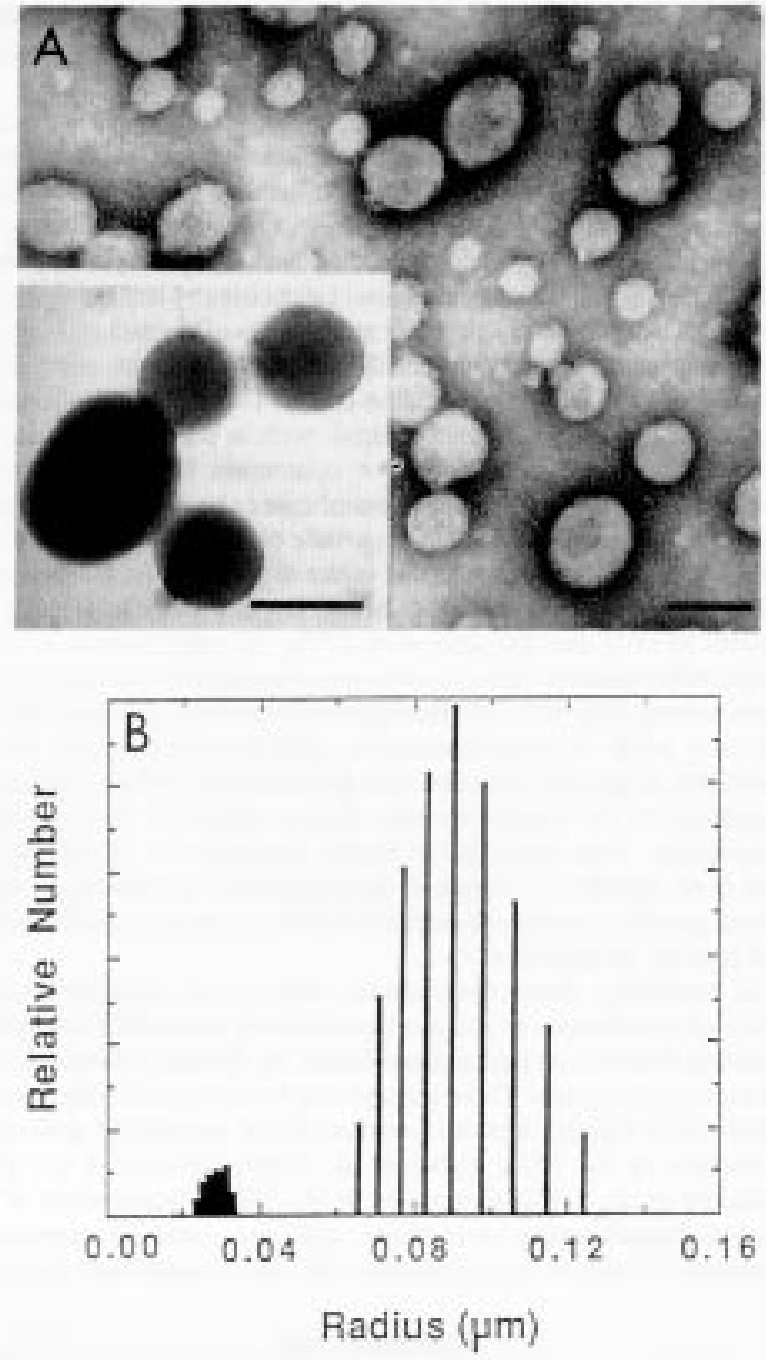

Fig. 3. Morphology and size of nonsedimentable lipid-protein particles. (A) Electron micrographs of lipid-protein particles isolated from the petals of young, stage 2 carnation flowers and stained with uranyl acetate according to Yao et al. (1991a); bars $=0.1 \mu \mathrm{m}$. (B) Size distribution of lipid-protein particles isolated from the petals of young, stage 2 carnation flowers obtained by dynamic light scattering using a helium-neon laser (Hallett et al., 1989).

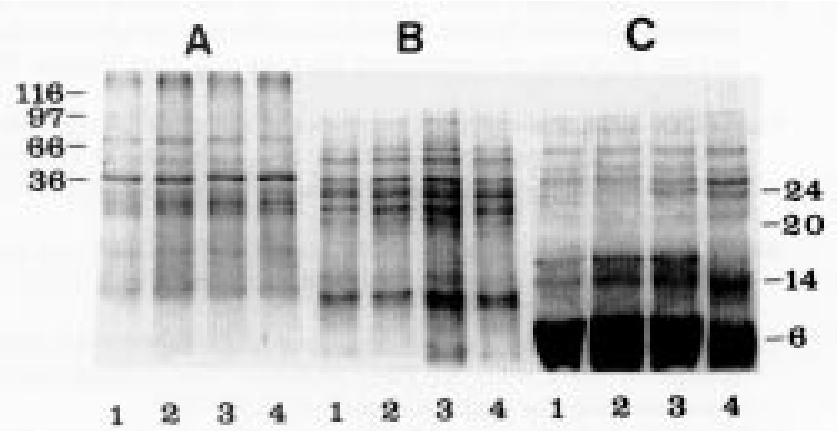

Fig. 4. SDS-PAGE (10\% to $20 \%$ linear gradient) of subcellular fractions isolated from the petals of carnation flowers. Each lane was loaded with 1 $\mu \mathrm{g}$ of protein, and the gels were stained with silver (Wray et al., 1981). (A) Microsomal membranes; (B) nonsedimentable lipid-protein particles; (C) particle-free cytosol. Fractions isolated: lane 1, from the petals of stage 1 flowers (partially closed flower buds); lane 2, from the petals of stage 2 flowers (petals fully expanded and flowers fully open with yellow-tinted centers); lane 3, from stage 3 flowers (fully open flowers without yellowtinted centers); lane 4 , from petals of stage 4 flowers (senescing flowers showing pronounced petal inrolling). cally free fatty acids and lipids that induce phase separations in membrane bilayers (Yao et al., 1991a, 1991b).

The contention that peroxidized lipids formed in membranes are released by blebbing from the membrane surface is supported by the finding that nonsedimentable lipid-protein particles formed in vitro from isolated membranes also contain fluorescent peroxidized lipids. For example, fractionation of the supernatant resulting from treatment of microsomal membranes from bean cotyledons with $\mathrm{Ca}^{2+}$ to activate phospholipid catabolism revealed that $\approx 65 \%$ of the fluorescent peroxidized lipids released are associated with nonsedimentable lipidprotein particles, and the remaining $35 \%$ is in the particle-free supernatant (Table 2). Microsomal membranes from carnation petals and from bean cotyledons both exhibit lipoxygenase activity that is inhibited by n-propyl gallate (Lynch and Thompson, 1984; Lynch et al., 1985). n-Propyl gallate also inhibits the formation of fluorescent peroxidized lipids in microsomal membranes as well as blebbing of nonsedimentable lipid-protein particles (Table 3). These observations collectively indicate that the lipoxygenase reaction facilitates the formation of nonsedimentable lipid-protein particles, and that peroxidized lipids formed by the lipoxygenase reaction may be among the promptor molecules that engender blebbing.

\section{Impairment of blebbing may account for accumulation of peroxidized lipids in senescing membranes}

Several indirect lines of evidence suggest that the capability of membranes to release molecular catabolites by blebbing of lipidprotein particles is impaired with advancing senescence. Specifically, free fatty acids accumulate in membranes as tissues senesce (Fobel et al., 1987), and gel-phase-forming phospholipid catabolites also accumulate in senescing membranes (Barber and Thompson, 1983; Legge et al., 1982; McKersie and Thompson, 1979; Platt-Aloia and Thomson, 1985). Both of these compounds appear to be removed in young tissue by blebbing, thus leading to the formation of nonsedimentable lipid-

Table 2. Fluorescence of lipid extracts from fractions obtained by treating microsomal membranes from 2-day-old bean cotyledons with $\mathrm{Ca}^{2+}$ to activate phospholipid catabolism and release lipid-protein $(\mathrm{L}-\mathrm{P})$ particles by blebbing.

\begin{tabular}{lc}
\hline \hline Fractions & $\begin{array}{c}\text { Percentage of } \\
\text { total fluorescence }\end{array}$ \\
\hline Supernatant containing nonsedimentable & 100 \\
$\begin{array}{l}\text { L-P particles } \\
\text { Nonsedimentable L-P particles }\end{array}$ & $64.4 \pm 9.2$ \\
Filtrate & $35.6 \pm 5.5$
\end{tabular}

${ }^{\mathrm{z} N o n s e d i m e n t a b l e ~ L-P}$ particles were generated from $10 \mathrm{mg}$ protein equivalents of microsomal membranes. The supernatant containing nonsedimentable L-P particles was obtained by centrifuging the reaction mixture after treatment with $\mathrm{Ca}^{2+}$, and the L-P particles were isolated from the supernatant by ultrafiltration as described (Yao et al., 1993a).

yFluorescence emission was recorded at $430 \mathrm{~nm}$ (360 $\mathrm{nm}$ excitation). Standard errors of the means are indicated; $\mathrm{n}=3$. Data are from Yao et al. (1993a)

Table 3. Inhibitory effect of n-propyl gallate on the formation of fluorescent peroxidized lipids and on blebbing of nonsedimentable lipid-protein (NS L-P) particles during treatment of microsomal membranes with $\mathrm{Ca}^{2+}$ to activate phospholipid catabolism. ${ }^{2}$

\begin{tabular}{lc}
\hline Action & Percent inhibition \\
\hline $\begin{array}{l}\text { Formation of fluorescent } \\
\text { peroxidized lipids in } \\
\quad \text { microsomal membranes }\end{array}$ & \\
$\begin{array}{l}\text { Blebbing of NS L-P particles } \\
\text { from microsomal membranes }\end{array}$ & $47.5 \pm 7.5$ \\
\hline
\end{tabular}

${ }^{\mathrm{z}}$ Microsomal membranes (10 $\mathrm{mg}$ protein equivalent) from 2-day-old bean cotyledons were treated with $\mathrm{Ca}^{2+}$ in the presence and absence of $2 \mathrm{~mm}$ n-propyl gallate as described (Yao et al., 1993a) to initiate lipid peroxidation and blebbing of NS L-P particles.

'Fluorescence emission was recorded at $430 \mathrm{~nm}$ (excitation $360 \mathrm{~nm}$ ). The standard error of the mean is indicated; $\mathrm{n}=3$.

${ }^{x}$ Formation of lipid-protein particles was quantified as the release of lipid phosphate. The standard error of the mean is indicated; $\mathrm{n}=3$. 
McKersie, B.D., J.R. Lepock, J. Kruuv, and J.E. Thompson. 1978. The effects of cotyledon senescence on the composition and physical properties of membrane lipids. Biochim. Biophys. Acta 508:197-212.

McKersie, B.D. and J.E. Thompson. 1979. Phase properties of senescing plant membranes. Role of neutral lipids. Biochim. Biophys. Acta 550:48-58.

Pauls, K.P. and J.E. Thompson. 1984. Evidence for the accumulation of peroxidized lipids in membranes of senescing cotyledons. Plant Physiol. 75:1152-1157.

Platt-Aloia, K. and W.W. Thomson. 1985. Freeze-fracture evidence of gelphase lipid in membranes of senescing cowpea cotyledons. Planta 163:360369.

Tappel, A.L. 1975. Lipid peroxidation and fluorescent molecular damage to membranes, p. 145-170. In: B.F. Trump and A. Arstila (eds.). Pathobiology of cell membranes. Academic, New York.

Thompson, J.E., R.L. Legge, and R.F. Barber. 1987. The role of free radicals in senescence and wounding. New Phytol. 105:317-344.

Thompson, J.E., S. Mayak, M. Shinitzky, and A.H. Halevy. 1982. Acceleration of membrane senescence in cut carnation flowers by treatment with ethylene. Plant Physiol. 69:859-863.
Wilhelm, J. and N. Wilhelnova. 1981. Accumulation of lipofuscin-like pigments in chloroplasts from senescent leaves of Phaseolus vulgaris. Photosynthetica 15:55-60.

Wray, W.W., T. Bovikas, V.P. Wray, and R. Hancock. 1981. Silver staining of proteins in polyacrylamide gels. Anal. Biochem. 118:197-203.

Yao, K., G. Paliyath, R.W. Humphrey, F.R. Hallett, and J.E. Thompson. 1991a. Identification and characterization of nonsedimentable lipid-protein microvesicles. Proc. Natl. Acad. Sci. USA 88:2269-2273.

Yao, K., G. Paliyath, and J.E. Thompson. 1991b. Nonsedimentable microvesicles from senescing bean cotyledons contain gel phase-forming phospholipid degradation products. Plant Physiol. 97:502-508.

Yao, K., G. Paliyath, and J.E. Thompson. 1993a. Localization of peroxidized lipids in nonsedimentable microvesicles of senescing bean cotyledons. J. Expt. Bot. 44:1267-1274.

Yao, K. and J.E. Thompson. 1993. Enrichment of proteinase activity in deteriosomes, a new class of microvesicles. FEBS Lett. 323:99-103.

Yao, K., X. Wu, J.E. Thompson, and J.C. Carlson. 1993b. Isolation and characterization of deteriosomes from rat liver. J. Cell Physiol. 51:488-494.

\title{
Toward a Comprehensive Model for Lipid Peroxidation in Plant Tissue Disorders
}

\author{
Robert L. Shewfelt \\ Center for Food Safety and Quality Enhancement, University of Georgia, Griffin, GA 30223-1797 \\ Albert C. Purvis \\ Department of Horticulture, Coastal Plain Station, University of Georgia, Tifton, GA 31793
}

Lipid peroxidation has been observed during the development of metabolic disorders in plant (Shewfelt and Erickson, 1991; Winston, 1990) and animal tissues (Kehrer, 1993; Pacifici and Davies, 1991). A partial list of recent reports linking lipid peroxidation to plant disorders, senescence, and aging is shown in Table 1. It is not clear whether peroxidation represents a primary cause or merely a secondary effect of these disorders. Lipid peroxidation and associated defense mechanisms in the cell occur via an exceedingly complex process. While certain steps appear to be nonenzymic chemical reactions governed strictly by kinetics (Buettner, 1993), others are clearly under genetic control (Kane et al., 1993). Statements to proclaim or dismiss lipid peroxidation as the primary cause of these disorders have been based on oversimplification of the processes involved. The case against a causative role is based on the variability of cell and tissue response to various types of stress and the frequent lack of evidence of peroxidative product accumulation before onset of the disorder (see Table 2 for recent examples). The objective of this review is not to catalog lipid oxidation in plant stresses, but to provide a framework for evaluating a cause-and-effect relationship in these disorders. This article presents an overview of peroxidative processes in plant tissues, a comprehensive model to explain how peroxidation of membrane lipids could function to cause disorders, specific explanations for problematical observations of affected tissue, and implications of the model if the theory is correct. The proposed model is an amplification and extension of one described earlier (Purvis and Shewfelt, 1993; Shewfelt and Erickson, 1991).

\section{PEROXIDATION IN PLANT TISSUE}

Lipid peroxidation is a natural consequence of metabolic processes in the cell, occurring via initiation, propagation, and termination reactions (Schaich, 1992; Winston, 1990). Active oxygen species such as superoxide $\left(\mathrm{O}_{2}^{-}\right)$and hydrogen peroxide $\left(\mathrm{H}_{2} \mathrm{O}_{2}\right)$ are by-products of

The cost of publishing this paper was defrayed in part by the payment of page charges. Under postal regulations, this paper therefore must be hereby marked advertisement solely to indicate this fact. electron transport in chloroplasts, mitochondria, and plasma membranes (Winston, 1990). Interaction of superoxide and hydrogen peroxide with iron species $\left(\mathrm{Fe}^{2+}, \mathrm{Fe}^{3+}\right)$ in membranes leads to formation of lipid-free radicals, presumably via formation of the hydroxyl radical (HO.) (Borg and Schaich, 1988) or by an iron intermediate that is most active as the $\mathrm{Fe}^{2+}: \mathrm{Fe}^{3+}$ ratio approaches 1.0 (Minotti and Aust, 1992). Singlet oxygen $\left({ }^{1} \mathrm{O}_{2}\right)$ is formed in chloroplasts during photosynthesis (Chakraborty and Tripathy, 1992) and is highly reactive with lipids (Bradley and Min, 1992).

Lipid hydroperoxides ( $\mathrm{LOOH})$ are also formed in plant tissue by lipoxygenase (LOX) (Gardner, 1991). Unlike the free radical processes described above, lipoxygenase, acting under aerobic conditions, does not produce lipid-free radicals. In addition, lipoxygenases in plant tissue either require or preferentially attack free fatty acids (Hildebrand, 1989), usually acting in concert with hydrolytic enzymes (Leshem, 1992).

For each source of lipid peroxidation within the cell there is a defense mechanism. Thus, superoxide can be degraded to hydrogen peroxide by superoxide dismutase (SOD) and hydrogen peroxide can be further degraded to water and oxygen by catalase. Alpha-tocopherol, $\beta$-carotene, and ascorbic acid will scavenge free radicals, including the hydroxyl radical (Buettner, 1993), while carotenoids (DiMascio et al., 1989) and ubiquinone (Cabrini et al., 1986) quench singlet oxygen. Lipoxygenase activity is controlled by compartmentation (Elstner, 1991) and by maintaining the fatty acids in the esterified form (Hildebrand, 1989).

Despite the presence of defense systems, membrane lipids are peroxidized, probably via generation of the hydroxyl radical in the membrane in close proximity to a polyunsaturated fatty acid (PUFA). The resultant lipid peroxyl radical will be quickly converted to a lipid hydroperoxide by interaction with $\alpha$-tocopherol or other hydrogen donors (Fig. 1) (Buettner, 1993). One $\alpha$-tocopherol molecule is estimated to protect from 220 (Cogrel et al., 1993) to 1000 (Buettner, 1993) phospholipid molecules within a membrane. Rapid mobility of $\alpha$-tocopherol in the bilayer is achieved by the association of its polar head group with the polar head group of phosphatidylcholine (PC) (Urano et al., 1993). The tocopheroxyl radical is more stable than a 


\section{WORKSHOP}

Table 1. Recent references supporting a link between lipid peroxidation and plant tissue disorders or senescence and aging.

\begin{tabular}{|c|c|c|}
\hline Inducer & Description & Reference \\
\hline Calcium deficiency & $\begin{array}{l}\text { Correlation between necrosis and catalytic activity of superoxide dismutase in } \\
\text { Solanum tuberosum L. tubers }\end{array}$ & Monk-Talbot et al., 1991 \\
\hline Chilling & $\begin{array}{l}\text { Suggests resistant Lycopersicon hirsutum Humb. \& Bonpl. decreases production of active } \\
\text { oxygen species at low temperatures }\end{array}$ & Walker and McKersie, 199 \\
\hline Heat and light & $\begin{array}{l}\text { Decreased electron transport in Triticum aestivum L. leaves linked to peroxidation } \\
\text { of thylakoid lipids }\end{array}$ & Mishra and Singhal, 1992 \\
\hline \multirow[t]{2}{*}{ Microbial attack } & $\begin{array}{l}\text { Formation of free radicals in Solanum tuberosum L. tubers that are infected } \\
\text { with Erwinia carotovora }\end{array}$ & Deighton et al., 1992 \\
\hline & $\begin{array}{l}\text { Oxidative response is one of earliest signals in hypersensitive response } \\
\text { in Glycine max Merr. cells }\end{array}$ & Legendre et al., 1993 \\
\hline Paraquat $^{z}$ & $\begin{array}{l}\text { Increased activity of antioxidant enzymes in drought-resistant } \\
\text { Zea mays L. strain }\end{array}$ & Pastori and Trippi, 1993 \\
\hline Pollutants & $\begin{array}{l}\text { In vitro demonstration of ozone-induced damage to Populus maximowizii A. Henry } \\
\text { rubisco via membrane lipids }\end{array}$ & Landry and Pell, 1993 \\
\hline Water deficit & $\begin{array}{l}\text { Resistance capacity of lipid extracts to peroxidation are affected by drought in } \\
\text { Phaseolus vulgaris L. leaves }\end{array}$ & Ferrari-Iliou et al., 1993 \\
\hline Aging & $\begin{array}{l}\text { Suggests gradual accumulation of free-radical products in Solanum tuberosum } \mathrm{L} \text {. } \\
\text { tubers but not consistent with lipoxygenase }\end{array}$ & Kumar and Knowles, 1993 \\
\hline Senescence & $\begin{array}{l}\text { Increased lipid peroxidation products detected during senescence of } \\
\text { Petroselinum crispum Mill. leaves }\end{array}$ & Meir et al., 1992 \\
\hline
\end{tabular}

Table 2. Recent references that do not support a link between lipid peroxidation and plant tissue disorders.

\begin{tabular}{|c|c|c|}
\hline Inducer & Description & Reference \\
\hline$\overline{\text { Bisulfite }}$ & $\begin{array}{l}\text { Evidence of protein damage to photosystem II occurs before evidence of lipid peroxidation } \\
\text { in Phaseolus vulgaris L. leaves }\end{array}$ & Covello et al., 1989 \\
\hline Chilling & $\begin{array}{l}\text { Differences in sensitivity of Cucumis sativus L. leaves not explained on the basis of } \\
\text { vulnerability to superoxide or presence of SOD }\end{array}$ & Hodgson and Raison, 1991 \\
\hline Dehydration & $\begin{array}{l}\text { Degree of fatty acid unsaturation does not decrease and production of superoxide did not } \\
\text { increase in Helianthus annus L. seedling thylakoids }\end{array}$ & Sgherri et al., 1993 \\
\hline Light or methylviologen & $\begin{array}{l}\text { Elevated cystolic glutathione reductase in leaves of transgenic Nicotiana tabacum } \mathrm{L} \text {. } \\
\text { plants did not affect oxidative balance }\end{array}$ & Foyer et al., 1991 \\
\hline \multirow[t]{2}{*}{ Microbial attack } & $\begin{array}{l}\text { Oxidative burst in Trifolium repens L. and Nicotiana tabacum L. is independent of } \\
\text { phytoalexin production and hypersensitive response }\end{array}$ & Devlin and Gustine, 1992 \\
\hline & $\begin{array}{l}\text { Free radical scavenger tests indicate that } \cdot \mathrm{OH} \text { and LOX are not involved in stress ethylene } \\
\text { production of Glycine max Merr. cuttings }\end{array}$ & Pennazio and Roggero, 1992 \\
\hline Paraquat $^{2}$ & $\begin{array}{l}\text { Higher levels of chloroplast SOD in transgenic Nicotiana tabacum L. plants did not } \\
\text { prevent } \mathrm{O}_{2}^{-} \text {toxicity }\end{array}$ & Tepperman and Dunsmuir, 1990 \\
\hline \multirow[t]{3}{*}{ Aging } & No measurable loss of PUFA observed in Typha latifolia $\mathrm{L}$. pollen & van Bilsen and Hoekstra, 1993 \\
\hline & $\begin{array}{l}\text { Absence of LOX isozymes in transgenic Glycine max Merr. seeds did not increase } \\
\text { resistance to accelerated aging }\end{array}$ & Wang et al., 1990 \\
\hline & No free-radical accumulation associated with loss of viability of Triticum aestivum L. seeds & Girard and LeMeste, 1992 \\
\hline Senescence & $\begin{array}{l}\text { Tocopherol levels in Petroselinum sativum Mill. and Apium graveolens L. leaves do not } \\
\text { decrease predictably }\end{array}$ & Rise et al., 1989 \\
\hline
\end{tabular}

${ }^{2}$ Gramoxone(1,1'-dimethyl-4-4'-bypridinium ion) (paraquat).

phospholipid free radical and can be regenerated by the oxidation of ascorbic acid to dehydroascorbic acid (Buettner, 1993), which in turn can be regenerated by the oxidation of glutathione and additional oxidation-reduction reactions in the cell (Meister, 1992). In addition, glutathione protects protein thiols in the membrane in the presence and absence of $\alpha$-tocopherol (Palamanda and Kehrer, 1993). Note that since lipoxygenase produces lipid hydroperoxides directly without the free-radical intermediate (Gardner, 1991), lipoxygenase-catalyzed peroxidation does not lead directly to tocopheroxyl-radical formation. The action of lipoxygenase on lipids is also specific to the position of the double bond.

Lipid hydroperoxides increase the hydrophilic character of the internal bilayer (Frenkel, 1991). Relative to the active oxygen species and lipid radicals, lipid hydroperoxides are stable (Leshem, 1992), but they will degrade to undesirable free radicals (Schaich, 1992). Membrane repair systems have been identified that remove hydroperoxides by selective hydrolysis (Pacifici and Davies, 1991) and detoxify them by reactions coupled to glutathione reductase and nonspecific peroxidases (Salin, 1988).

In the absence of the necessary defense and repair systems, freeradical chain propagation of lipid peroxidation occurs within the membrane. As lipid hydroperoxides degrade, the lipid free radicals come into contact with other polyunsaturated fatty acids such that 10 to 100 additional lipid hydroperoxides are formed before the chain is broken (Niki et al., 1991). The rate of propagation is a factor of the interaction of lipid peroxyl radicals and polyunsaturated fatty acids in the membrane. This interaction is affected by both the concentration of available polyunsaturated fatty acids and the fluidity of the membrane. Although fluidity is frequently described in terms of chainordering, as affected by degree of unsaturation of fatty acids, rotational and lateral diffusion are more important factors in fluidity of membrane lipids (Carruthers and Melchior, 1988; Leshem, 1992; Webb and Green, 1991).

\section{A COMPREHENSIVE MODEL}

In the context of this view of lipid peroxidation, a model of peroxidative degradation of plant tissue can be constructed to explain the similarities and differences observed in plant tissue disorders. The model (Fig. 2) is offered to provide a basis for systematically testing the role of lipid peroxidation in the etiology of plant tissue disorders. It is consistent with most of the data collected to date, but has not been conclusively demonstrated.

Under normal conditions in the cell, active oxygen species are produced. Most of these species are scavenged or quenched by primary defense mechanisms, and little peroxidation of membrane lipids and proteins occurs. Any peroxidized lipids and proteins are quickly repaired. Upon exposure of plant tissue to stress, however, the level of active oxygen species tends to increase (Walker and McKersie, 1993). Stress may also induce the synthesis of defense molecules such as the antioxidant enzymes - superoxide dismutase, catalase, ascorbate peroxidase, and glutathione peroxidase (Mishra et al., 1993). Upon 

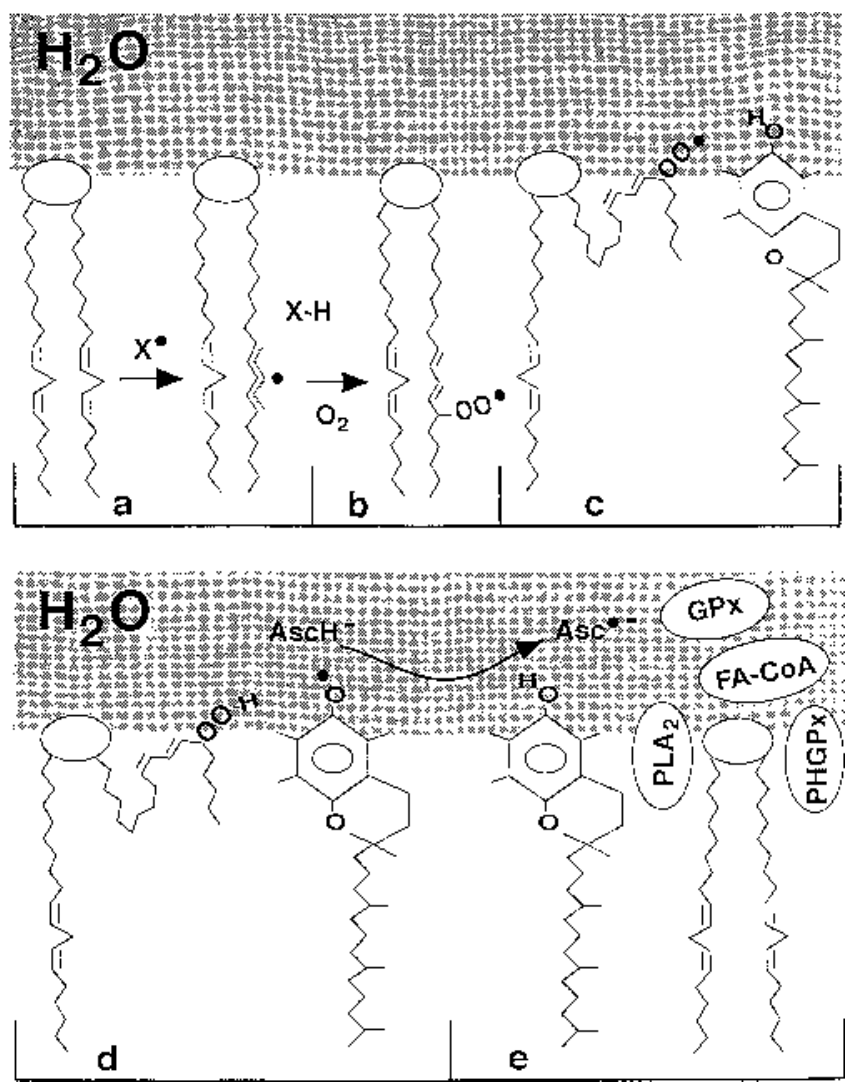

Fig. 1. Membrane lipid peroxidation. Only one leaflet of the bilayer is represented. (a) Initiation of the peroxidation process by an oxidizing radical, $\mathrm{X}$; by abstraction of a bis-allylic hydrogen, thereby forming a pentadienyl radical. (b) Oxygenation to form a peroxyl radical and a conjugated diene. (c) Peroxyl radical moiety partitions to the watermembrane interface where it is poised for repair by tocopherol. (d) Peroxyl radical is converted to a lipid hydroperoxide, and the resulting tocopherol radical can be repaired by ascorbate. (e) Tocopherol has been recycled by ascorbate; the resulting ascorbate radical can be recycled by enzyme systems. The enzymes phospholipase $\mathrm{A}_{2}\left(\mathrm{PLA}_{2}\right)$, phospholipid hydroperoxide glutathione peroxidase (PH-GPx), glutathione peroxidase (GPx), and fatty acyl-coenzyme A (FA-CoA) cooperate to detoxify and repair the oxidized fatty acid chain of the phospholipid. This cartoon cannot show the dynamic aspects of this process. Tocopherol (TOH) in the membrane will undoubtedly be bobbing "up and down" so that the position of the "OH" is variable. In addition, $\mathrm{TOH}$ and TO" may have somewhat differing positions at the interface. Reprinted from Archives of Biochemistry and Biophysics [Buettner (1993) 300:535-543] with permission.

prolonged exposure, however, the level of prooxidants can exceed the defense capacity of the cell, or a specific membrane in the cell, against peroxidative attack. The tipping of this balance from net defense to net peroxidation could result from a continued increase in prooxidant formation, a decrease in one or more of the primary defense mechanisms, or a combination of these events (Purvis and Shewfelt, 1993). Although lipids and proteins are subject to free-radical attack, lipid peroxidation is kinetically favored (Murphy et al., 1992). Thus, if the process is regulated strictly by kinetics, peroxidation of polyunsaturated fatty acids may serve a protective function to prevent direct attack on proteins. Evidence in some animal systems suggests that protein damage is incurred by direct attack (Pacifici and Davies, 1991).

As lipid free radicals are converted to lipid hydroperoxides, $\alpha$ tocopherol concentrations decrease, particularly when ascorbic acid, glutathione, and other cell reductants in contact with the affected membrane(s) are depleted. When the tocopherol concentration in the membrane is too low to protect the lipids, free-radical chain propagation occurs much faster than the repair mechanisms can function. Modification of the physical properties of the membrane (Bruch and Thayer, 1983) and direct peroxidation of proteins by lipid free radicals (Murphy et al., 1992) lead to decreased protein activity (Thomas et al.,
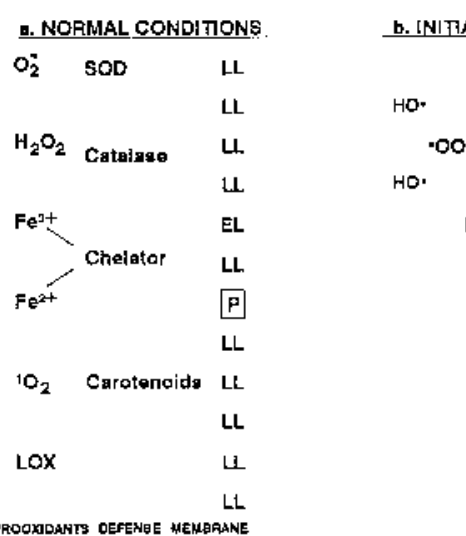

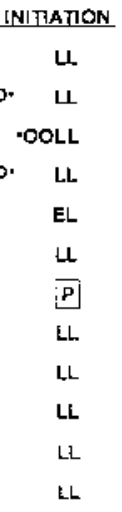

E. CHAIN-BLOCKING

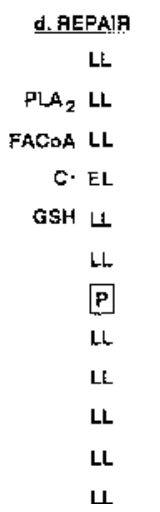

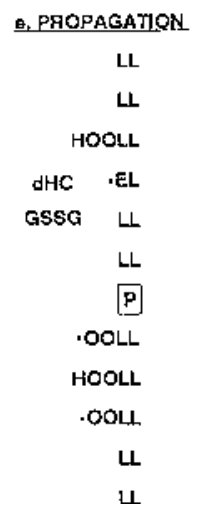

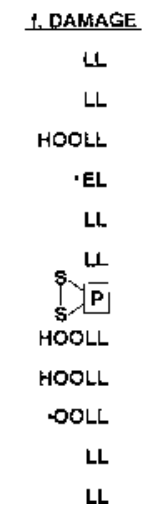

Fig. 2. A comprehensive model depicting free-radical attack of membrane lipids, initiation, chain-blocking, repair, propagation, and protein damage, where $\mathrm{O}_{2}^{-}$represents superoxide; $\mathrm{H}_{2} \mathrm{O}_{2}$, hydrogen peroxide; $\mathrm{Fe}^{3+}$, ferric iron; $\mathrm{Fe}^{2+}$, ferrous iron; ${ }^{1} \mathrm{O}_{2}$, singlet oxygen; LOX, lipoxygenase; SOD, superoxide dismutase; L, phospholipid molecule with two fatty acids; E, $\alpha$ tocopherol; $\mathrm{P}$, membrane-bound protein; $\mathrm{HO} \bullet$, hydroxyl radical; $\bullet \mathrm{OOLL}$, lipid peroxyl radical; HOOLL, lipid hydroperoxide; $\bullet$ E, tocopherol radical; $\mathrm{PLA}_{2}$, phospholipase $\mathrm{A}_{2} ; \mathrm{FACoA}$, fatty acyl coenzyme A; $\mathrm{C}$, ascorbic acid radical; GSH, glutathione; dHC, dehydroascorbic acid; GSSG, oxidized glutathione; $\bullet \mathrm{OL}$, lipid alkoxyl radical; and $\mathrm{S}>\mathrm{P}$, a protein with a disulfide bond at an active site implying damage. Under normal conditions, defense mechanisms protect the membrane from peroxidation. Initiation occurs when oxygen radicals, such as $\bullet \mathrm{OH}$, overcome the defense system to form -OOL (see Fig. $1 \mathrm{a}$ and b). Chain-blocking is achieved by $\alpha$-tocopherol forming HOOLL and $\bullet E$ (Fig. $1 \mathrm{c}$ and d). Repair occurs by cleavage of the radical to $\mathrm{C} \bullet$ (Fig. 1e). Propagation results upon depletion of enough E, C, and GSH such that $\bullet$ OOLL and HOOLL are formed more rapidly than repair mechanisms can be effective. Damage to proteins is incurred through interaction with an adjacent $\cdot$ OOLL

1989), metabolic imbalances, cellular dysfunction, and ultimately tissue disorders.

Although no comprehensive study of peroxidative degradation of a specific membrane has been conducted with respect to a specific disorder in a plant tissue, a wide range of studies supports specific steps in the proposed model. In addition to the evidence presented in Table 1 , increased superoxide generation has been noted in hypersensitive response (Adam et al., 1989; Keppler and Novacky, 1987). Formation of the hydroxyl radical in microsomes isolated from seedlings has been documented (Simontacchi and Puntarulo, 1992). Initial increases in the levels of antioxidant enzymes have been reported during winter hardening of red spruce (Picea rubeus Sarg.) (Doulis et al., 1993), of herbicide-treated leaves (Schmidt and Kunert, 1986), and in manganese-deficient plants exposed to high-intensity light conditions (Cakmak and Marschner, 1992). Decreases in levels of antioxidant enzymes have been reported during chilling of susceptible seedlings (Jahnke et al., 1991) and dehydration of germinating seeds (Leprince et al., 1990). Superoxide dismutase activity decreases in mitochondria of senescing petals while increasing in the peroxisomes of the same petals (Droillard and Paulin, 1990). Depletion of cellular, water-soluble antioxidants 
has been observed during hydration of seed axes (Senaratna et al., 1985) and chilling of susceptible fruit (Hariyadi and Parkin, 1991). Alpha-tocopherol levels decrease in thylakoids from chilled fruit before evidence of injury (Hariyadi and Parkin, 1991). Measurable levels of peroxidative products have been observed before symptom development of hypersensitive reaction (Adam et al., 1989) and loss of desiccation tolerance (Leprince et al., 1990). Evidence of lipidprotein peroxidative complexes detected by fluorescent pigment methodology has been described in senescing leaves (Meir et al., 1992) and chilled fruit (Hariyadi and Parkin, 1991).

\section{EXPLANATIONS}

A comprehensive model for lipid peroxidation as the primary cause of plant tissue disorders must explain contrary evidence, the wide variability of symptoms observed for a diverse set of stimuli, the delay between stress induction and evidence of peroxidation, cross protection observed between stress responses, localized damage as noted in hypersensitive reaction and chilling injury $(\mathrm{CI})$, and the enhancement of CI observed upon rewarming.

Evidence against lipid peroxidation as a causal agent in plant tissue disorders can be categorized by failure to observe an increase in a specific oxidative species (Sgherri et al., 1993), inability to relate sensitivity to stress on the basis of specific antioxidants or scavenging enzymes (Foyer et al., 1991; Hodgson and Raison, 1991; Rise et al., 1989; Tepperman and Dunsmuir, 1990), the lack of a relationship between lipoxygenase activity and the disorder (Pennazio and Roggero, 1992; Wang et al., 1990), and the lack of selective decreases in polyunsaturated fatty acids (Sgherri et al., 1993; van Bilsen and Hoekstra, 1993). The proposed model suggests that, rather than focusing on a single event (e.g., increase in an active oxygen species or decrease in activity of a specific enzyme), the overall balance between prooxidants and defense reactions must be studied. Much of the research has focused on superoxide production and superoxide dismutase defenses, but if superoxide dismutase is present and catalase is deficient then hydrogen peroxide could accumulate to toxic levels. In addition, compartmentation of enzymes and substrates in the cell, ignored by most of the studies cited in Tables 1 and 2, would be expected to affect the oxidative balance at a particular membrane site. For example, if superoxide is produced and is able to migrate to a membrane site outside compartments containing superoxide dismutase, the superoxide could be converted to the hydroxyl radical via the Haber-Weiss reaction, with damage incurred at cellular superoxide dismutase levels that appear to be sufficient for protection. Exposure of susceptible and resistant leaves to chilling conditions resulted in increases in production of active oxygen species and antioxidant enzyme activity in both species (Walker and McKersie, 1993). Decreased susceptibility was attributed to a more rapid decline in subsequent production of active oxygen species in the resistant species, supporting the suggestion that an understanding of the balance of prooxidants and defense mechanisms is the critical area of study in lipid peroxidation research.

The proposed model is based on the premise that damage to a single membrane system (e.g., plasma membrane, thylakoid, inner mitochondrial membrane) in the cell is sufficient to induce metabolic disorders and tissue injury. Thus, measurement of total cellular polyunsaturated fatty acids may not reveal significant losses of polyunsaturated fatty acids in the affected membrane. The model is based on initiation and propagation of lipid free radicals in the membrane and considers formation of the hydroxyl radical in the presence of $\mathrm{Fe}^{2+}$, $\mathrm{Fe}^{3+}$, and singlet oxygen to be primary initiators of peroxidative degradation in plant membranes. Lipoxygenase is probably not a major factor in causing these disorders. Transgenic soybean seeds with decreased lipoxygenase were not more resistant to accelerated aging (Wang et al., 1990). More likely, however, hydrolytic enzymes and lipoxygenase are part of a programmed turnover or retailoring mechanism rather than being responsible for membrane degradation and resultant tissue disorders.

In this model, the wide variability in response and symptom development in diverse types of plant tissue to the same stress or similar types of tissue to various stresses is attributed to differences in loss of protein function (e.g., ion transport, enzyme activity) in the membrane that is the site of attack. Studies on CI have shown differences in susceptibility of organs as influenced by genotype (Bodner and Larcher, 1978) as well as differences in susceptibility of specific membranes in a cell (Cheng and Shewfelt, 1988; Marangoni et al., 1989). The development of symptoms would result from the specific metabolic imbalances incurred by disruption of specific enzymes in the affected membrane or loss of membrane permeability. While the membrane site of attack would vary from tissue to tissue and potentially from stress to stress, the membrane of greatest susceptibility to a specific stress within a particular organ should always be the same, and response, including symptom development, should be predictable based on the function of that particular membrane in that cell in that particular organ.

The delay between stress induction and evidence of peroxidation can be explained by a greater understanding of the peroxidation process. Comparing the rate of reaction of active oxygen species occurring within nanoseconds or microseconds (Buettner, 1993) and the development of symptoms measured in hours (Adam et al., 1989), days (Cakmak and Marschner, 1992; Jahnke et al., 1991; Leprince et al., 1990), or weeks (Cheng and Shewfelt, 1988) suggests that the process is slow and incremental. Most of the peroxidation products measured as thiobarbituric acid-reactive substances (TBA-RS) and fluorescent pigments would not be expected to accumulate until late in the response process, probably during the propagation stage (Winston, 1990) and then only in the affected membrane. Thus, it should not be surprising that, in some tissues, evidence of these types of peroxidation could coincide with evidence of injury. Earlier measures of peroxidation, such as the presence of conjugated dienes, changes in electron spin resonance (ESR), and depletion of $\alpha$-tocopherol or $\beta$-carotene in the affected membrane, should precede evidence of symptoms.

Mitigating treatments, such as cold acclimation (Doulis et al., 1993; Shewfelt, 1992), temperature conditioning (Hatton, 1990), and cross protection from one stress to another (Lurie et al., 1991; Shaaltiel et al., 1988), are attributed in this model to induction of defense mechanisms in the susceptible membrane at sublethal levels of stress exposure. Likewise, localized responses observed in hypersensitive reaction (Keppler and Novacky, 1987) and pitting, a symptom of CI in many fruits (Hatton, 1990; Jackman et al., 1988), may represent signaling from cells that are directly affected, permitting adjacent cells to synthesize new antioxidants to prevent injury. Thus, those cells exposed to direct microbial attack or earlier exposure to low temperatures within microclimates would induce defense mechanisms in adjacent cells, enabling them to survive.

One of the striking features of CI in harvested products is that symptoms not evident during chilling exposure develop rapidly upon rewarming (Jackman et al., 1988). If chilling is prolonged, however, symptoms usually will appear. A potential explanation for this phenomenon is that lipid hydroperoxides formed are stable enough at low temperatures that defense and repair processes present are sufficient to prevent propagation. As the temperature is raised, however, the breakdown of preformed lipid hydroperoxides in the affected membrane could occur more rapidly than the recovery of defense and repair mechanisms.

\section{IMPLICATIONS OF THE MODEL}

If the proposed model provides an accurate view of changes in the cell in response to the conditions described, we must change our view of stress physiology in plant tissue. The model as proposed suggests that 1) chemical processes in the membrane play a more direct role in development of disorders than biochemical (enzymic) processes; 2) the common link between many, if not all, membrane-associated disorders is free-radical propagation in the most susceptible membrane; 3 ) the critical oxidative process and susceptible membrane are nonspecific in plant response to stress but specific and predictable within a particular organ in response to a specific stress; and 4) headgroup mobility is as important as degree of fatty acid unsaturation in the development of these disorders.

One difficulty in conducting lipid peroxidation research is the lack of specificity of key antioxidants. Ascorbate, $\beta$-carotene, glutathione, 
and $\alpha$-tocopherol are all multifunctional (Winston, 1990). Thus, the effects on peroxidation of adding any of these compounds cannot be attributed to a single function. This lack of specificity of these molecules implies that the reaction kinetics in nonenzymic processes are at least as important as their role in enzyme-catalyzed reactions (Reed, 1990). Many of the primary defense reactions are enzymic in nature, such as those catalyzed by superoxide dismutase and catalase, as well as some repair reactions catalyzed by ascorbate peroxidase, glutathione reductase, and hydrolytic enzymes. These enzymes represent the ability of a cell to respond to increased levels of peroxidation. The disorder develops, however, as chemical reactions in a cell occur more rapidly than one or more of the critical enzymes is able to respond at the site. Thus, the breaching of the defense and repair mechanisms at the most susceptible membrane could be the result of a deficiency in a limiting enzyme, and that critical enzyme could vary from tissue to tissue. Genetic manipulation to control these disorders will require identifying the particular critical defense enzyme in the tissue studied. Overexpression of a critical enzyme might not alleviate the disorder if more than one enzyme is limiting. Also, much emphasis in membraneassociated disorders has been placed on membrane fluidity, usually with respect to chain ordering as determined by fatty acid unsaturation (Shewfelt, 1992; Webb and Green, 1991). If free-radical propagation is the critical step in the process as proposed in the model, then physical interactions of lipid free radicals with other polyunsaturated fatty acids would be as important as the concentration of the polyunsaturated fatty acids. Lateral and rotational diffusion, as controlled by the mobility of the lipid headgroup, plays a major role in fatty acid interaction within the membrane (Carruthers and Melchior, 1988; Leshem, 1992).

The importance of compartmentation within the cell cannot be overemphasized (Elstner, 1991; Schaich, 1992). The model suggests that a single membrane within the cell might be attacked, leading to dysfunction and even cell death. Thus, localized defense and repair or lack of defense and repair could be critical in the prevention or development of a disorder. Zhu and Scandalios (1992) demonstrated increased resistance to oxidative stress by increasing Mn superoxide dismutase expression, confined to mitochondria, in a deficient yeast strain.

This model provides a framework for systematically testing the role of membrane lipid peroxidation in the etiology of plant tissue disorders. It implies that future work must be directed at the specific membrane that is being attacked rather than at cellular membranes as a whole. Modifying genes either to limit production of active oxgyen species or to increase synthesis of an antioxidant enzyme should not be attempted without prior or concurrent identification of the primary site of attack and the factor(s) causing the imbalance leading to net peroxidation. The causal factor(s) should be the target of the genemodification studies. In addition to measuring products of lipid peroxidation, studies should also follow disappearance of antioxidants, such as $\alpha$-tocopherol and carotenoids, associated with the membrane of interest as well as cellular reductants, such as ascorbic acid and glutathione, to determine whether depletion precedes evidence of peroxidation. Furthermore, developing better means of assessing the progress of peroxidation in vivo is essential. Future studies expected to contribute to our understanding of peroxidative degradation of membranes include those that 1) can successfully partition healthy and unhealthy domains of cells within tissue that has been exposed to a specific stress and 2) provide an evolution of peroxidative degradation by histochemistry.

\section{Literature Cited}

Adam, A., T. Farkas, G. Somlyai, M. Hevesi, and Z. Kiraly. 1989. Consequence of $\mathrm{O}_{2}^{-}$generation during a bacterially induced hypersensitive reaction in tobacco: Deterioration of membrane lipids. Physiol. Mol. Plant Pathol. 34:13-26.

Bodner, M. and W. Larcher. 1987. Chilling susceptibility of different organs and tissues of Saintpaulia ionatha and Coffea arabica. Agnew. Botanik. 61:225-242.

Borg, D.C. and K.M. Schaich. 1988. Iron and hydroxyl radicals in lipid oxidation: Fenton reactions in lipid and nucleic acids co-oxidized with lipid, p. 427-441. In: P.A. Cerutti, I. Fridovich, and J.M. McCord (eds.).
Oxy-radicals in molecular biology and pathology. Alan R. Liss, New York. Bradley, D.G. and D.B. Min. 1992. Singlet oxygen oxidation of foods. Crit. Rev. Food Sci. Nutr. 31:211-236.

Bruch, R.C. and W.S. Thayer. 1983. Differential effect of lipid peroxidation on membrane fluidity as determined by electron spin resonance probes. Biochim. Biophys. Acta. 733:216-222.

Buettner, G.R. 1993. The pecking order of free radicals and antioxidants: Lipid peroxidation, $\alpha$-tocopherol, and ascorbate. Arch. Biochem. Biophys. 300:535-543.

Cabrini, L., B. Pasquali, B. Tadolini, A.M. Sechi, and L. Landi. 1986. Antioxidant behavior of ubiquinone and $\beta$-carotene incorporated in model membranes. Free Radical Res. Commun. 2:85-92.

Cakmak, I. and H. Marschner. 1992. Magnesium deficiency and high light intensity enhanced activities of superoxide dismutase, ascorbate peroxidase, and glutathione reductase in bean leaves. Plant Physiol. 98:12221227.

Carruthers, A. and D.L. Melchior. 1988. Role of bilayer lipids in governing membrane transport processes, p. 201-225. In: R.C. Aloia, C.C. Curtain, and L.M. Gordon (eds.). Lipid domains and the relationship to membrane function. Alan R. Liss, New York.

Chakraborty, N. and B.C. Tripathy. 1992. Involvement of singlet oxygen in 5aminolevolinic acid-induced photodynamic damage of cucumber (Cucumis sativus L.) chloroplasts. Plant Physiol. 98:7-11.

Cheng, T.-S. and R.L. Shewfelt. 1988. The effect of chilling exposure of tomatoes during subsequent ripening at ambient temperature. J. Food Sci. 53:1160-1162

Cogrel, P., et al. 1993. The relationship between fatty acid peroxidation and $\alpha-$ tocopherol consumption in isolated normal and transformed hepatocytes. Lipids 28:115-119.

Covello, P.S., A. Chang, E.B. Dumbroff, and J.E. Thompson. 1989. Inhibition of photosystem II precedes thylakoid membrane lipid peroxidation in bisulfite-treated leaves in Phaseolus vulgaris. Plant Physiol. 90:14921497.

Deighton, N., D.J. Johnston, S.M. Glidewell, G.D. Lyon, and B.A. Goodman 1992. The involvement of oxygen-derived free radicals in the resistant response of potato tubers to Erwinia carotovora. Protoplasma 171:167169.

Devlin, W.S. and D.L. Gustine. 1992. Involvement of the oxidative burst in phytoalexin accumulation and the hypersensitive response. Plant Physiol. 100:1189-1195.

DiMascio, P., S. Kaiser, and H. Sies. 1989. Lycopene as the most efficient biological carotenoid singlet oxygen quencher. Arch. Biochem. Biophys. 274:532-538.

Doulis, A.G., et al. 1993. Antioxidant response and winter hardiness in red spruce (Picea rubens, Sarg.). New Phytol. 123:365-374.

Droillard, M.-J. and A. Paulin. 1990. Isozymes of superoxide dismutase in mitochondria and peroxisomes isolated from petals of carnation (Dianthus caryophyllus) during senescence. Plant Physiol. 94:1187-1192.

Elstner, E.F. 1991. Mechanisms of oxygen activation in different compartments of plant cells, p. 13-25. In: E.J. Pell and K.L. Steffen (eds.). Active oxygen/oxidative stress and plant metabolism. Amer. Soc. Plant Physiol., Rockville, Md.

Ferrari-Iliou, R., et al. 1993. In vitro phytodynamic lipid peroxidation of total lipophilic extracts from leaves of bean plants. Biochim. Biophys. Acta 1166:48-54.

Frenkel, C. 1991. Disruption of macromolecular hydration-A possible origin of chilling destabilization of biopolymers. Trends Food Sci. Technol. 2:3941

Foyer, C., M. Lelandais, C. Galap, and K.J. Kunert. 1991. Effects of elevated cytosolic glutathione reductase activity on the cellular glutathione pool and photosynthesis in leaves under normal and stress conditions. Plant Physiol. 97:863-872.

Gardner, H.W. 1991. Recent investigations into the lipoxygenase pathway of plants. Biochim. Biophys. Acta. 1084:221-239.

Girard, J. and M. LeMeste. 1992. Lack of relationship between free radical levels determined by ESR technique and viability of wheat seeds. C.R. Acad. Sci. Paris 314, Ser. III:417-422.

Hariyadi, P. and K.L. Parkin. 1991. Chilling-induced oxidative stress in cucumber fruits. Postharvest Biol. Technol. 1:33-45.

Hatton, T.T. 1990. Reduction of chilling injury with temperature manipulation, p. 270-280. In: C.-Y. Wang (ed.). Chilling injury of horticultural crops. CRC Press, Boca Raton, Fla

Hildebrand, D.F. 1989. Lipoxygenases. Physiol. Plant. 76:249-253.

Hodgson, R.A.J. and J.K. Raison. 1991. Lipid peroxidation and superoxide dismutase activity in relation to photoinhibition induced by chilling in moderate light. Planta 185:215-219.

Jackman, R.L., R.Y. Yada, A. Marangoni, K.L. Parkin, and D.W. Stanley. 1988 Chilling injury. A review of quality aspects. J. Food Qual. 11:253-278.

Jahnke, L.S., M.R. Hull, and S.P. Long. 1991. Chilling stress and oxygen 
metabolizing enzymes in Zea mays and Zea diploperennis. Plant Cell Environ. 14:97-104.

Kane, D.J., et al. 1993. Bco-2 inhibition of neural death: Decreased generation of reactive oxygen species. Science 262:1274-1277.

Kehrer, J.P. 1993. Free radicals as mediators of tissue injury and disease. Crit. Rev. Toxicol. 23:21-48.

Keppler, L.D. and A. Novacky. 1987. The initiation of membrane lipid peroxidation during bacteria-induced hypersensitive reaction. Physiol. Mol. Plant Pathol. 30:233-245.

Kumar, G.N.M. and N.R. Knowles. 1993. Changes in lipid peroxidation and lipolytic free-radical scavenging enzyme activities during aging and sprouting of potato (Solanum tuberosum) seed-tubers. Plant Physiol. 102:115-124.

Landry, L.G. and E.J. Pell. 1993. Modification of rubisco and altered proteolytic activity of $\mathrm{O}_{3}$-stressed hybrid poplar (Populus maximowizii $\mathrm{X}$ trichoeanpa). Plant Physiol. 101:1355-1362.

Legendre, L., S. Rueter, P.F. Heinstein, and P.S. Low. 1993. Characterization of the oligogalacturonide-induced oxidative burst in cultured soybean (Glycine max) cells. Plant Physiol. 102:233-240.

Leprince O., R. Deltour, P.C. Thorpe, N.M. Atherton, and G.A.F. Hendry. 1990. The role of free radicals and radical processing systems in loss of desiccation tolerance in germinating maize (Zea mays L.). New Phytol. 116:573-580.

Leshem, Y.Y. 1992. The plant membrane: A biophysical approach to structure, development and senescence. Kluwer Press, Amsterdam, The Netherlands.

Lurie, S., J.D. Klein, and R. Ben Arie. 1991. Prestorage heat treatment delays superficial scald on 'Granny Smith' apples. HortScience 26:166-167.

Marangoni, A.G., A.K. Smith, R.Y. Yada, and D.W. Stanley. 1989. Ultrastructural changes associated with chilling injury in mature-green tomato fruit. J. Amer. Soc. Hort. Sci. 114:958-962.

Mead, J.F. 1976. Free radical mechanisms of lipid damage and consequences for cellular membranes, p. 51-68. In: W.A. Pryor (ed.). Free radicals in biology. vol. 1. Academic, New York.

Meir, S., S. Philosoph-Hadas, and N. Aharoni. 1992. Ethylene-increased accumulation of fluorescent lipid-peroxidation products detected during senescence of parsley by a newly developed method. J. Amer. Soc. Hort. Sci. 117:128-132.

Meister, A. 1992. On the antioxidant effects of ascorbic acid and glutathione. Biochem. Pharmacol. 44:1905-1915.

Minotti, G. and S.D. Aust. 1992. Redox cycling of iron and lipid peroxidation. Lipids 27:219-226.

Mishra, P.M., R.K. Mishra, and G.S. Singhal. 1993. Changes in the activities of anti-oxidant enzymes during exposure of intact wheat leaves to strong visible light at different temperatures in the presence of protein synthesis inhibitors. Plant Physiol. 102:903-910.

Mishra, R.K. and G.S. Singhal. 1992. Function of photosynthetic apparatus of intact wheat leaves under high light and heat stress and its relationship with peroxidation of thylakoid lipids. Plant Physiol. 98:1-6.

Monk-Talbot, L.S., H.V. Davies, M. Macaulay, and M.P. Foster. 1991. Superoxide dismutase and susceptibility of potato (Solanum tuberosum L.) tubers to calcium related disorders. J. Plant Physiol. 137:499-501.

Murphy, M.E., H. Scholich, and H. Sies. 1992. Protection by glutathione and other thiol compounds against the loss of protein thiols and tocopherol homologs during microsomal lipid peroxidation. Eur. J. Biochem. 210:139146.

Niki, E., Y. Yamamoto, E. Kamuro, and K. Sato. 1991. Membrane damage due to lipid oxidation. Amer. J. Clin. Nutr. 53:2015-2055.

Pacifici, R.E. and K.J.A. Davies. 1991. Protein, lipid and DNA repair systems in oxidative stress: The free radical theory of aging revisited. Gerontology 37:166-180.

Palamanda, J.R. and J.P. Kehrer. 1993. Involvement of vitamin E and protein thiols in the inhibition of microsomal lipid peroxidation by glutathione. Lipids 28:427-431.

Pastori, G.M. and V.S. Trippi. 1993. Antioxidative protection in a droughtresistant maize strain during leaf senescence. Physiol. Plant. 87:227-231.

Pennazio, S. and P. Roggero. 1992. Effects of free radical scavengers on stress ethylene in soybean leaves hypersensitively reacting to tobacco necrosis virus. Ann. Bot. 69:437-439.

Purvis, A.C. and R.L. Shewfelt. 1993. Does the alternative pathway ameliorate chilling injury in sensitive plant tissues? Physiol. Plant. 88:712-718.

Reed, G.A. 1990. Co-oxidation of environmental toxic agents by lipid peroxyl species, p. 155-180. In: C. Vigo-Pelfrey (ed.). Membrane lipid oxidation. vol. 1. CRC Press, Boca Raton, Fla.

Rise, M., M.Cojocaru, H.E. Gottlieb, and E.E. Goldschmidt. 1989. Accumulation of a-tocopherol in senescing organs as related to chlorophyll degradation. Plant Physiol. 89:1028-1030.

Salin, M.L. 1988. Toxic oxygen species and protective systems of the chloroplast. Physiol. Plant. 72:681-689.

Schaich, K.M. 1992. Metals and lipid oxidation. Contemporary issues. Lipids 27:209-218.
Schmidt, A. and K.J. Kunert. 1986. Lipid peroxidation in higher plants-The role of glutathione reductase. Plant Physiol. 82:700-702.

Senaratna, T., B.D. McKersie, and R.H. Stinson. 1985. Antioxidant levels in germinating soy-bean seed axes in relation to free radical and dehydration tolerance. Plant Physiol. 78:168-171.

Sgherri, C.L.M., C. Pinzino, and F. Navari-Izzo. 1993. Chemical changes and $\mathrm{O}_{2}^{-}$production in thylakoid membranes under water stress. Physiol. Plant. 87:211-216.

Shaaltiel, Y., A. Glazer, P.F. Bocion, and J. Gressel. 1988. Cross tolerance to herbicidal and environmental oxidants of plant biotypes tolerant to paraquat, sulfur dioxide, and ozone. Pesticide Biochem. Physiol. 31:13-23.

Shewfelt, R.L. 1992. Response of plant membranes to chilling and freezing, p. 192-219. In: Y.Y. Leshem (ed.). The plant membrane: A biophysical approach to structure, development and senescence. Kluwer Press, Amsterdam, The Netherlands.

Shewfelt, R.L. and M.C. Erickson. 1991. Role of lipid peroxidation in the mechanism of membrane-associated disorders in edible plant tissue. Trends Food Sci. Technol. 2:152-154.

Simontacchi, M. and S. Puntarulo. 1992. Oxygen radical generation by isolated microsomes from soybean seedlings. Plant Physiol. 100:1263-1268.

Tepperman, J.M. and P. Dunsmuir. 1990. Transformed plants with elevated levels of chloroplastic SOD are not more resistant to superoxide toxicity. Plant Mol. Biol. 14:501-511.

Thomas, S.M., G.M. Gebiki, and R.T. Dean. 1989. Radical initiated $\alpha$ tocopherol depletion and lipid peroxidation in mitochondrial membranes. Biochim. Biophys. Acta. 1002:189-197.

Urano, S., et al. 1993. Mobility and molecular orientation of vitamin $\mathrm{E}$ in liposomal membranes as determined by ${ }^{19} \mathrm{~F}$ NRM and fluorescence polarization techniques. Arch. Biochem. Biophys. 303:10-14.

van Bilsen, D.G.J.L. and F.A. Hoekstra. 1993. Decreased membrane integrity in aging Typha latifolia L. pollen. Plant Physiol. 101:675-682.

Walker, M.A. and B.D. McKersie. 1993. Role of the ascorbate-glutathione antioxidant system in chilling resistance of tomato. J. Plant Physiol. 141:234-239.

Wang, J., K. Fujimoto, T. Miazawa, Y. Endo, and K. Kitamura. 1990. Sensitivities of lipoxygenase-lacking soybean seeds to accelerated aging and their chemiluminescence levels. Phytochemistry 29:3739-3742.

Webb, M.S. and B.R. Green. 1991. Biochemical and biophysical properties of thylakoid acyl lipids. Biochim. Biophys. Acta 1060:133-158.

Winston, G.W. 1990. Physicochemical basis for free radical formation in cells: Production and defenses. In: R.G. Alscher and J.R. Cumming (eds.). Stress response in plants: Adaptation and acclimation mechanisms. Wiley-Liss, New York.

Zhu, D. and J.G. Scandalios. 1992. Expression of the maize MnSOD (SOD 3) gene in MnSOD-deficient yeast rescues the mutant yeast under oxidative stress. Genetics 131:803-809. 